\title{
Motorcycle Steering Oscillations due to Road Profiling
}

\author{
D. J. N. Limebeer ${ }^{1}$ \\ Department of Electrical and \\ Electronic Engineering, \\ Imperial College of Science \\ Technology and Medicine, \\ Exhibition Road, \\ London SW7 2BT, UK
}

R. S. Sharp

School of Engineering,

Cranfield University,

Whittle Building,

Bedford MD43 OAL, UK

\section{S. Evangelou}

Department of Electrical and

Electronic Engineering, Imperial College of Science

Technology and Medicine,

Exhibition Road,

London SW7 2BT, UK
A study of the effects of regular road undulations on the dynamics of a cornering motorcycle is presented. This work is based on an enhanced version of the motorcycle model described in "A Motorcycle Model for Stability and Control Analysis" (R. S. Sharp and D. J. N. Limebeer, 2001, Multibody Syst. Dyn., Vol. 6, No. 2, pp. 123-142). We make use of root-locus and frequency response plots that were derived from a linearized version of this model; the linearization is for small perturbations from a general steady-cornering equilibrium state. The root-locus plots provide information about the damping and resonant frequencies of the key motorcycle modes at different machine speeds, while the frequency response plots are used to study the propagation of road forcing signals to the motorcycle steering system. Our results are based on the assumption that there is road forcing associated with both wheels and that there is a time delay between the front and rear wheel forcing signals-this is sometimes referred to as wheelbase filtering. As has been explained before, control systems are used in the nonlinear simulation code to establish and maintain the machine's speed and roll angle at preset values (for flat road running). These controllers are used to find the machine's equilibrium state and not to emulate a rider's control actions. The results show that at various critical cornering conditions, regular road undulations of a particular wavelength can cause severe steering oscillations. At low speeds the machine is susceptible to road forcing signals that excite the lightly damped wobble and front suspension pitch modes. At higher speeds it is the weave and front wheel hop modes that become vulnerable to road forcing. We believe that the results and theory presented here explain many of the stability related road accidents that have been reported in the popular literature and are therefore of practical import. The models used in this research make use of the multibody modelling package AUTOSIM (Autosim $2.5+$ Reference Manual, 1998, Mechanical Simulation Corporation) and are available at the web site http://www.ee.ic.ac.uk/control/motorcycles/. The motorcycle and tire parameters can be found at the end of the code. [DOI: 10.1115/1.1507768]

\section{Introduction}

It has been known for a long time that single-track vehicles can be unstable. Prior research has examined this issue in the context of small perturbations from straight running ([1-3]), and small perturbations from steady-state cornering $([4-6])$. Oscillatory instabilities are clearly problematic and lightly damped resonances are commonplace. It is clear that there is a possibility that these lightly damped modes could be excited by regular road surface undulations. As we will now explain, there is a persuasive body of nontechnical evidence that suggests that these forced oscillations are an illusive source of danger for the riders of powerful motorcycles.

In the established wisdom ([7]) low-frequency weave oscillations are associated with high-speed operation, while higherfrequency wobble, or wheel shimmy resonances, are associated with lower speeds. There is some anecdotal evidence to suggest that wobble frequency steering oscillations can also occur at much higher machine speeds. Collectively, these phenomena are the basis of a notable class of accidents that involve no other road users. Although this type of accident has been known for a long time, it has proved remarkably difficult to obtain a complete understanding of the mechanics involved. There appear to be at least four reasons for this: First, single-track vehicle out-of-control accidents are usually poorly documented and are often not witnessed by

\footnotetext{
${ }^{1}$ To whom correspondence should be addressed.

Contributed by the Applied Mechanics Division of THE AMERICAN SOCIETY OF MECHANICAL ENGINEERS for publication in the ASME JOURNAL OF APPLIED MECHANICS. Manuscript received by the ASME Applied Mechanics Division, October 21, 2001; final revision, March 6, 2002. Associate Editor: O. O'Reilly. Discussion on the paper should be addressed to the Editor, Prof. Robert M. McMeeking, Department of Mechanical and Environmental Engineering, University of California-Santa Barbara, Santa Barbara, CA 93106-5070, and will be accepted until four months after final publication of the paper itself in the ASME JOURNAL OF APPLIED MECHANICS
}

independent observers. Secondly, there appears to be a tendency on the part of the investigating authorities and manufacturers to prematurely attribute them to "rider error." Thirdly, these events only occur under an unusual combination of circumstances involving the motorcycle type and setup, the speed, the lean angle, the rider's stature, and the road profile. This is consistent with the notion that the machine development process sometimes fails to reveal these behavioral problems. Finally, we will show that the underlying mechanisms are inherently complex.

A number of reports that describe these handling difficulties have appeared in the popular motorcycle press over the last ten years. Although these reports are based predominantly on anecdotal evidence, there is a compelling level of consistency between them. One example of a loss-of-control event occurred during police motorcycle training and the circumstances of this incident are summarized in the following extract from [8] " ... there is a specific section of road which can cause severe handling difficulties for motorcycles being ridden at high speed ... this section of road has a series of small undulations in it at the beginning of a large sweeping right hand bend..."

Another well-publicized event occurred at a relatively low speed under apparently benign circumstances ([9]): “ . . . we were approaching a village at no more than $65 / 70 \mathrm{mph}$, on a smooth road, on a constant or trailing throttle when, for no apparent reason, the bike went wildly out of control ...". This incident and some of the associated background are described in [10-13].

A high-profile fatal accident occurred, when according to an eye witness, the machine being ridden went into a violent "tank slapper" 2 at about $60 \mathrm{mph}$ as the rider was going around a gentle corner $([14])$. The offending machine model was subsequently recalled in the U.S. ([15]) as well as in the U.K. ([16]). In their

\footnotetext{
${ }^{2}$ This expression is used to describe an oscillation that causes the handle bars to
} swing from lock to lock. 
recall statement, the manufacturers said: “... the front wheel may oscillate, causing the handlebars to move rapidly from side to side when accelerating from a corner and/or (accelerating) over a rough road surface, commonly known as tank slapping..." . There was further speculation as to the possible causes of the difficulty and various tests were performed on the machine that involved changing tires, fitting a steering damper and changing the rear damper unit ([17]). Tire changes did not make a significant difference, but a new rear damper unit and a steering damper made a large improvement. One article claimed that riders who weigh over $95 \mathrm{~kg}(210 \mathrm{lbs})$ had not experienced the instability phenomena ([18]).

Resonance related difficulties are still being reported in the popular press in the context of modern motorcycles ([19]).

A remarkable video tape of a weave-type instability was taken during the 1999 Formula One Isle of Man TT race ([20]). Paul Orritt can be seen exiting the gentle left-hand bend at the top of Bray Hill on a Honda Fireblade at approximately $150 \mathrm{mph}$ when for no apparent reason his machine went into an uncontrollable $2-3 \mathrm{~Hz}$ oscillation. His motorcycle subsequently ran wide and crashed. "It just wouldn't come out of the tank slapper," he recalled. "I was no longer in control ... the trouble began immediately after I ran over a couple of bumps in the freshly laid road surface..." ([21]). Needless to say, the financial and social costs associated with a serious motorcycle accident can be high. The Metropolitan police estimate that the cost of a fatal accident involving one of their officers is approximately $£ 1.2 \mathrm{M}(\$ 1.7 \mathrm{M})$ ([22]). This reason alone is sufficient that the matter should be treated as important and urgent.

The free-steering system and the associated self-steering action is fundamental to the stability and dynamic response properties of all motorcycles and it produces several lightly damped oscillatory modes: wobble, weave, cornering weave, patter, shake, and so on $([4,5,23])$. For the purposes of the present study, it is convenient to distinguish straight-running motorcycle behavior from the more complex cornering case. When a motorcycle is upright and running in a substantially straight line, the in-plane motions such as bounce, pitch, and wheel hop are decoupled at first-order level from the out-of-plane motions such as the sideslip, yaw, and roll. When the machine is leaned over in cornering, the in-plane and out-of-plane motions are coupled and this cross-coupling increases with increased roll angle. As a consequence of this feature, mathematical models for the straight-running case are significantly simpler to derive than their cornering counterparts. Notwithstanding Koenen's excellent work ([5]), it seems fair to say that the effective analysis of motorcycle cornering behavior requires an automated multibody modeling software package ([4]). It is clear from the motorcycle dynamics literature that the study of motorcycle cornering effectively stagnated for almost 20 years and that computer assisted multibody modeling tools were needed to break this impasse. Such software has recently been applied to motorcycle dynamics studies $([3,4,23-25])$, facilitating considerable extensions to previous knowledge.

When a motorcycle is leaned over in cornering, the coupling terms that cause the in-plane and out-of-plane motions to interact provide a signal transmission path between road undulations and lateral motions. This mechanism provides the means whereby steering oscillations can be produced by road profiling. We believe that the theory and results presented here provide an explanation for most of the behavioral observations described above. In every case it will be assumed that the machine is operating in the neighborhood of an equilibrium cornering condition and we will concentrate on the excitation of steering oscillations.

The paper is concerned with quantifying the machine response to regular road undulations through theoretical analysis. More particularly, the strength of the steering response and the associated design parameter sensitivity problem are studied. The machine condition of interest involves cornering and consequently an elaborate mathematical model of the system is needed. The exist- ing state-of-the-art model ([4]) is extended to include road profile induced effects. The full nonlinear model is linearized for small perturbations about an equilibrium cornering state that is found from a simulation of the motorcycle-rider system on a smooth road. The linear, small perturbation, uncontrolled model is then subjected to sinusoidal road displacement forcing and the frequency responses are computed. The responses to forcing from both the front and rear wheels are considered. When studying the combined effects of front and rear wheel road forcing, a wheelbase travel time delay is introduced into the model that ensures that the two road wheel inputs are correctly phased. Section 2 contains a brief description of the mathematical model and the particular motorcycle being studied (Section 2.1), the modeling extensions required for road forcing studies (Section 2.2), a brief description of the various checks that were used to qualify the computer model (Section 2.3), and the role of the rider and the linearization process (Section 2.4). The results are presented and discussed in Section 3. Section 4 contains the conclusions and a brief commentary on the directions of future work.

\section{The Mathematical Model}

The motorcycle model used in this study is based on that given in Section 3 of [4] and the account given here will only describe the extensions needed for this study. Figure 1 shows the machine in its nominal configuration in static equilibrium with the key modeling points labeled as $p_{1}, \cdots, p_{14}$. The symbolic multibody modeling package AUTOSIM [26] was used to convert this conceptual model into a FORTRAN code that is used to produce the nonlinear simulation results, and a MATLAB M-file for the linearized model based studies.

The model contains the following components: a main frame with six degrees-of-freedom, a swinging arm and its associated rear suspension system, a body with a roll freedom relative to the main frame that is used to represent the upper body of the rider, a front frame with twist and steer freedoms, telescopic front forks, spinning road wheels, and dynamic tires. The road is assumed to be flat, or regularly profiled, and the motorcycle can travel anywhere in the horizontal plane.

2.1 The Machine. The machine and machine parameters are based on a large touring machine of an early 1980's design ([5]); some of its basic parameters are given in Table 1 . The interested reader can obtain a complete set of parameters from the website http://www.ee.ic.ac.uk/control/motorcycles/.

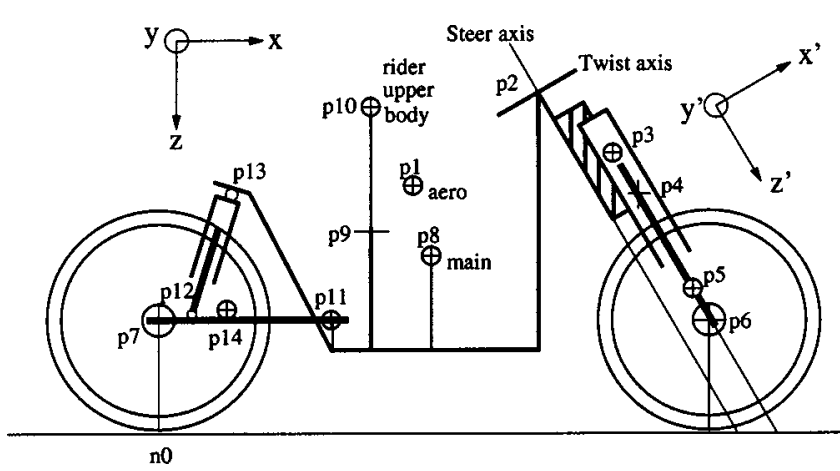

Fig. 1 Motorcycle model in its nominal configuration

Table 1 Machine parameters

\begin{tabular}{ll}
\hline \hline Total mass & $235 \mathrm{~kg}(518 \mathrm{lbs})$ \\
Maximum engine power & $65 \mathrm{~kW}(87 \mathrm{bhp})$ \\
Steering head angle & $30 \mathrm{deg}$ \\
Steering offset & $0.0659 \mathrm{~m}$ \\
Mechanical trail & $0.0924 \mathrm{~m}$ \\
\hline \hline
\end{tabular}




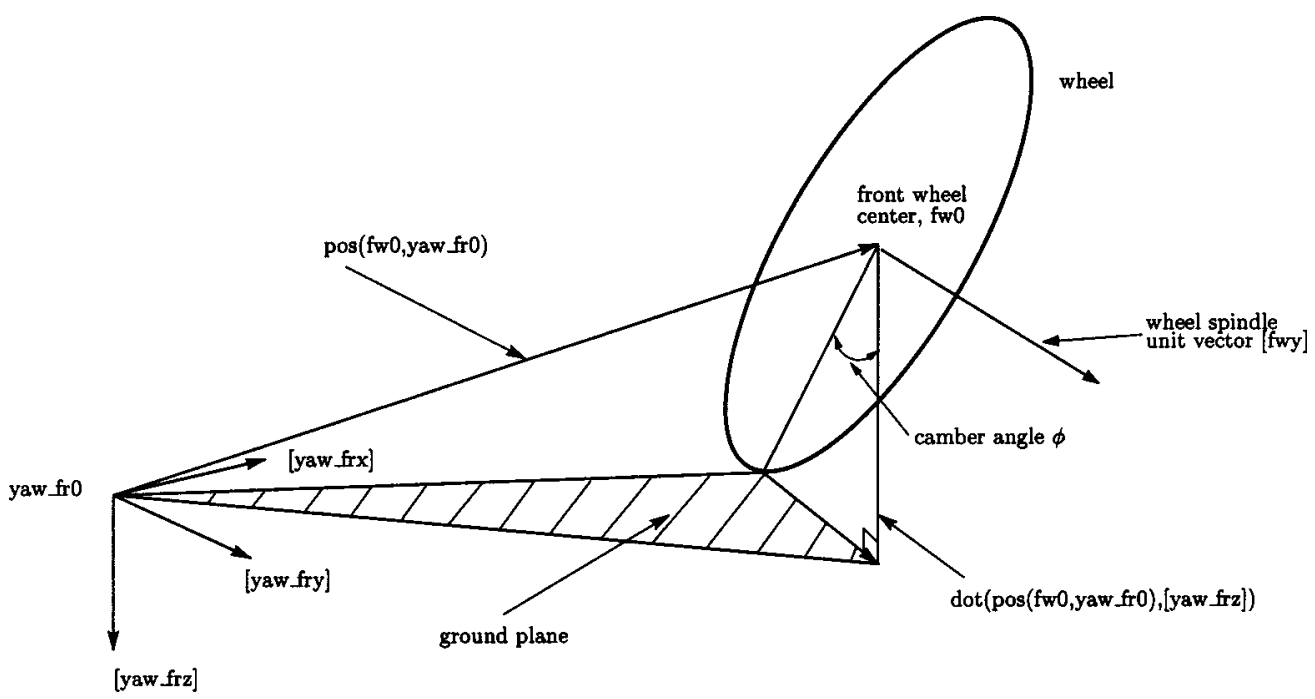

Fig. 2 Wheel and tire geometry, showing the migration of the ground contact point

2.2 Road Forcing. In order to introduce road forcing into the model, it is necessary to examine the road wheel ground contact geometry in some detail. We will assume that the road undulation amplitudes are small compared to the wheel radii and that their wavelengths are long.

The road wheel ground contact geometry is shown in detail in Fig. 2.

A vector along the line of intersection between the ground and wheel planes can be calculated via a cross product between vectors that are normal to these planes. Since the wheel spindle unit vector [fwy] is perpendicular to the wheel plane, and [yaw_frz] is a unit vector that is normal to the ground plane, we can use cross ( [fwy], [yaw_frz]) to generate the plane-intersection vector. The Appendix contains a brief description of the AUTOSIM instructions used here. The vector pointing from the wheel center to the ground contact point must be perpendicular to both the wheel spindle vector and the plane intersection vector. This vector is computed using the vector triple product $\operatorname{cross}\left(\operatorname{cross}\left([f w y],\left[y a w \_f r z\right]\right),[f w y]\right)$. To ensure that the triple product is a unit vector, we divide it by the sine of the angle between [yaw_frz] and [fwy] as follows:

$$
\begin{aligned}
& \operatorname{cross}\left(\operatorname{cross}\left([f w y],\left[y a w_{-} f r z\right]\right),[f w y]\right) / \\
& \operatorname{sqrt}\left(1-\operatorname{dot}\left([f w y],\left[y a w_{-} f r z\right]\right) * * 2\right) .
\end{aligned}
$$

Note that [fwy] is always perpendicular to cross ( $[f w y]$, [yaw_frz]) and consequently there is no need for a second normalization term. The vertical component of the vector joining the origin of the yaw frame axis system yaw_ $\mathrm{fw}_{\mathrm{w}} 0$ to the front wheel center $\mathrm{fw}_{\mathrm{w}} \mathrm{is}$ the height from the ground of the wheel center in the case of a smooth road and is computed as follows:

$$
\operatorname{dot}\left(\operatorname{pos}\left(f w 0, y_{\text {aw_fro }}\right),[\text { yaw_frz]). }\right.
$$

In the case of a profiled road, the height from the ground of the front wheel center is adjusted via a front wheel road height variable uf:

$$
\operatorname{dot}(\text { pos (yaw_fro, fw0), [yaw_frz])-uf. }
$$

Dividing the height by the camber angle gives the distance from the wheel center to the ground contact point:

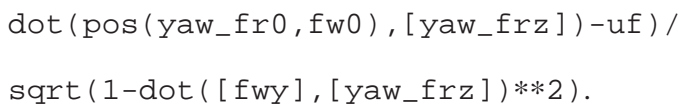

In the nominal condition, this distance is the wheel radius, so the tire radial deflection from the nominal can be found via a tire deflection calculation and this deflection is converted into a force change via the tire carcass radial stiffness. Combining this with the unit vector defined above, one obtains a vector with the correct magnitude and direction that points from the wheel spindle axis to the ground contact point:

$$
\begin{aligned}
& \operatorname{cross}\left(\operatorname{cross}\left([f w y],\left[y a w \_f r z\right]\right),[f w y]\right) * \\
& \left(\operatorname{dot}\left(\operatorname{pos}\left(y a w \_f r 0, f w 0\right),\left[y a w \_f r z\right]\right)-u f\right) / \\
& \left(1-\operatorname{dot}\left([f w y],\left[y a w \_f r z\right]\right) * * 2\right) .
\end{aligned}
$$

The contact point can now be defined via the coordinates of this vector as a moving point on the tire circumference. This point is used to calculate the sideslip angle and it is the point of application of the load and the sideforce. A parallel set of arguments apply to the rear road wheel.

2.3 Model Validation. The model validation processes used here are an evolution of those described elsewhere $([3,4])$. To maximize their effectiveness, they were designed to be substantially independent of the motorcycle model itself. Since we will only describe the updates to the checks described in our earlier work $([3,4])$, we suggest that the interested reader consults these papers as well as the modeling code that is located at the web site http://www.ee.ic.ac.uk/control/motorcycles.

The underlying principles behind the checks are that under equilibrium conditions: (i) the external forces acting on the motorcycle rider system must match the sum of the inertial and gravitational forces, (ii) the external moments acting on the motorcycle rider system must sum to zero and (iii) the power supply and dissipation must be equal.

The Force Balance. The force balance check ensures that under equilibrium cornering conditions the sum of the external forces is equal to the sum of the inertial and gravitational forces. To check the balance, the force error

$$
\mathbf{F}_{\text {error }}=\sum_{i} \mathbf{F}_{i}^{\mathrm{ext}}+\left(\sum_{j} m_{j}\right)(\mathbf{v} \times \boldsymbol{\omega}+\mathbf{g})
$$

was computed. The first sum contains the external forces, while the second sum contains the centripetal and gravitational forces. The $\mathbf{F}_{i}^{\text {ext }}$ 's include: (i) the aerodynamic lift and drag forces, (ii) the front and rear wheel normal loads, (iii) the tire side forces, 


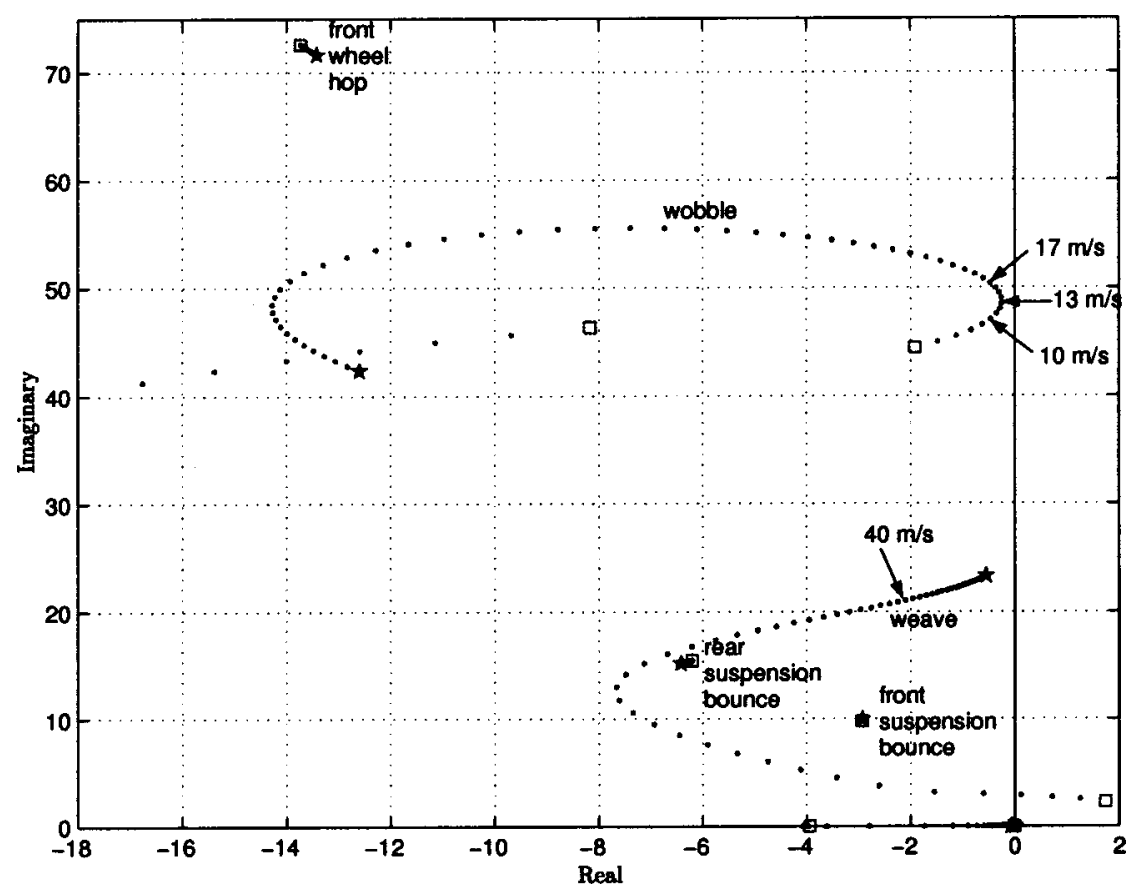

Fig. 3 Straight running root-locus with speed the varied parameter. The speed is increased from $5 \mathrm{~m} / \mathrm{s}(11 \mathrm{mph})(\square)$ to $60 \mathrm{~m} / \mathrm{s}(135 \mathrm{mph})(\star)$.

and (iv) the longitudinal driving and braking forces that act on the wheels at the ground contact points. In the second term, the $m_{j}$ 's are the machine's constituent masses, $\mathbf{v}$ is the velocity of the mass center of the main body, $\boldsymbol{\omega}$ is the main body yaw rate vector, and $\mathbf{g}$ is the gravitational acceleration vector. In our experience, one should achieve $\left|F_{\text {error }}\right|<4 N$, although many of the constituent forces have magnitudes of several thousands of Newtons.

The Moment Balance. In much the same way, it is possible to check that under equilibrium cornering conditions a moment error vector is zero. We compute

$$
\mathbf{M}_{\text {error }}=\sum_{i} \mathbf{l}_{i} \times m_{i}(\mathbf{v} \times \boldsymbol{\omega}+\mathbf{g})+\sum_{j} \mathbf{l}_{j} \times \mathbf{F}_{j}+\sum_{k} \mathbf{M}_{k} .
$$

The reference point for all the moment calculations is the rearwheel ground contact point. The $\mathbf{l}_{i}$ 's are moment arm vectors that point from the reference point to the appropriate mass centers and $m_{i}(\mathbf{v} \times \boldsymbol{\omega}+\mathbf{g})$ are the corresponding inertial and gravitational forces. The index $i$ ranges over each of the constituent masses. The second term contains all the external force-induced moments including: (i) the aerodynamic lift and drag forces, (ii) the front wheel normal load, (iii) the front wheel lateral tire forces and the (iv) the front tire longitudinal force. The $\mathbf{l}_{j}$ 's are moment arms that point from the reference point to the points of application of the various forces. The third term contains the gyroscopic moments due to the rates of change of angular momentum of the spinning road wheels under cornering, and the tyre moments. In our experience, one should achieve $\left|M_{\text {error }}\right|<5 \mathrm{Nm}$, although some of the constituent moments have magnitudes of several thousand Newton meters.

The Power Audit. This check is based on a "conservation of power" audit. The power source is the engine and the most important dissipators are the aerodynamic forces. Not surprisingly, a reliable checking process necessitates the inclusion of other effects to do with the tire forces and moments, some of which are subtle. The tires dissipate power via the longitudinal and lateral slip forces and this power dissipation is, in each case, computed via a dot product of the form $\mathbf{F} \cdot \mathbf{v}$ in which $\mathbf{F}$ is the force applied to the tread base material and $\mathbf{v}$ is the corresponding velocity. ${ }^{3}$ The longitudinal component of this velocity is the machine velocity multiplied by the tire's longitudinal slip, while the lateral component is the machine velocity multiplied by the tangent of the tire sideslip angle. The remaining dissipation effects are associated with the tires' aligning moments. These dissipation effects can be computed using expressions of the form M. $\boldsymbol{\omega}$ in which the M's are the aligning moments and the $\boldsymbol{\omega}$ 's are the wheel's angular velocity vectors. Our experience has been that the power checksum error should be no more than $1 \mathrm{~W}$.

2.4 Linearized Models and Frequency Response Calculations. The preparation of linearized models involves a two-step procedure. In the first, AUTOSIM is used to compute, symbolically, the linearized equations of motion. In the second, the nonlinear simulation code is used to find the equilibrium state associated with the steady-state cornering condition being studied. In order to expedite the convergence of the simulation to the required condition, the drive and steering torques are controlled by feedback loops. The drive torque is controlled so that the machine maintains a preset speed, while the steering torque is adjusted to maintain a desired roll angle. In a sense, the feedback control is simply part of an algorithm that is used to solve the motorcycle's equilibrium equations of motion. We have not attempted to replicate any active rider control actions for the following reasons:

1 Individual riders have their own styles and attempting to quantify the "typical rider" using computer code is little more than potentially misleading speculation.

2 Our focus here is on phenomena of $2-4 \mathrm{~Hz}$ (weave) and 6-8 $\mathrm{Hz}$ (wobble). The evidence suggests that most riders would find it difficult to react consistently to an unfamiliar weave-frequency type phenomenon and rider control intervention could make matters worse. Wobble frequency effects are effectively outside the rider's bandwidth and so in this case studying the uncontrolled machine is felt appropriate. The steering damping used here, with

\footnotetext{
${ }^{3}$ The required velocity is that of a material point of the tire that is currently the
} nominal contact point. This material point changes continuously as the wheel rotates. 


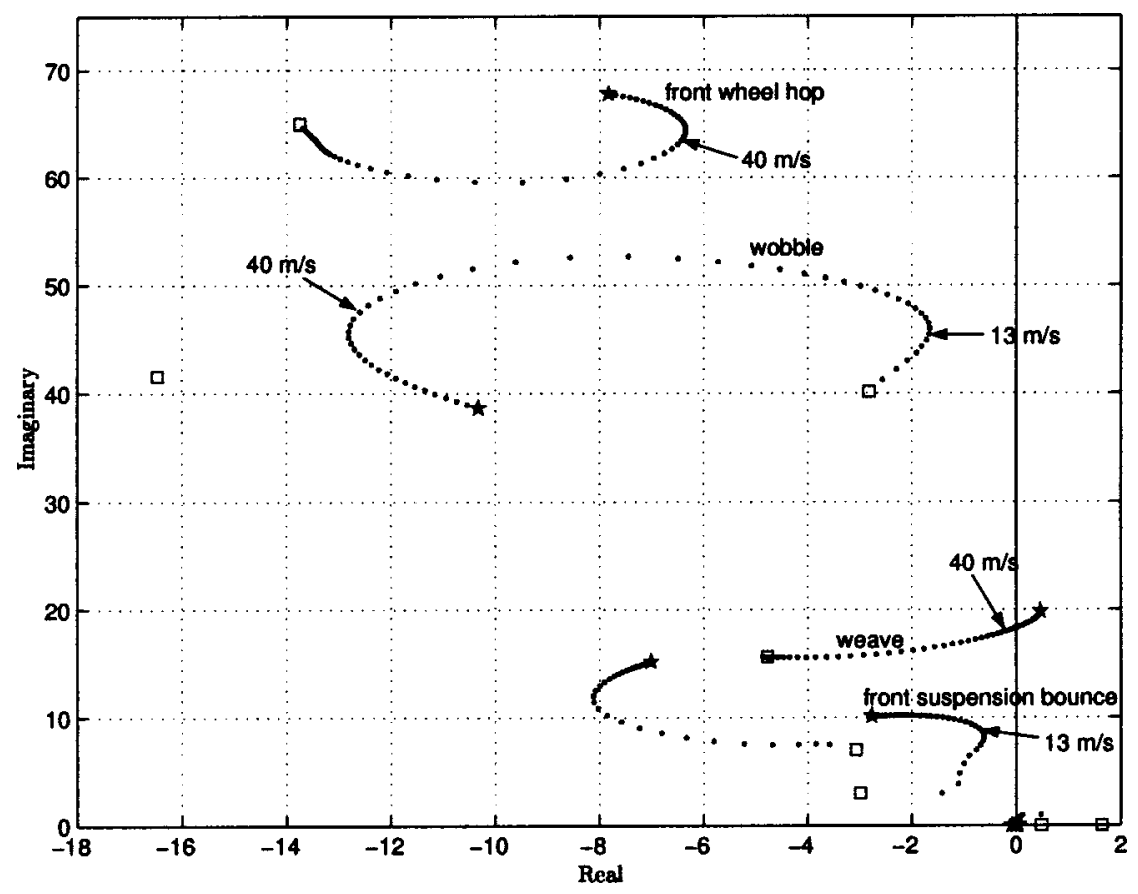

Fig. 4 Root-locus for a fixed roll angle of $30 \mathrm{deg}$. The speed is increased from $6 \mathrm{~m} / \mathrm{s}$ $(\square)$ to $60 \mathrm{~m} / \mathrm{s}(\star)$.

a nominal value of $7.4 \mathrm{Nm} /(\mathrm{rad} / \mathrm{s})$, is predominantly due to the rider's grip on the handlebars-this represents passive rather than active control.

3 Our aim is to characterize the properties of the machine in isolation, because a well-designed vehicle should behave safely even in the hands of riders who have limited skill and experience.

We will present a number of Bode (frequency response) plots that were calculated using linearized models computed by AUTOSIM. In our case, we used two inputs $u_{f}$ and $u_{r}$ that represent changes in the road height at the front and rear wheels' ground contact points, respectively. The steering angle $\delta$ was the only output. Let us now suppose that the state-space model, generated by AUTOSIM, that corresponds to a given cornering trim condition is

$$
\begin{gathered}
\dot{\mathbf{x}}=A \mathbf{x}+B \mathbf{u} \\
\delta=C \mathbf{x}
\end{gathered}
$$

in which

$$
\mathbf{u}=\left[\begin{array}{l}
u_{f} \\
u_{r}
\end{array}\right]
$$

The transfer functions that relate the front and rear road disturbance input to the steering angle are given by

$$
\left[\begin{array}{ll}
g_{f} & g_{r}
\end{array}\right]=C(s I-A)^{-1} B
$$

in which $s$ is the usual Laplace transform complex variable. One can study separately the influences of the front and rear roadwheel disturbances using $g_{f}(s)$ and $g_{r}(s)$ independently. In the case of studies of the combined influence of both wheels, the transfer function

$$
g(s)=g_{f}(s)+e^{-s r} g_{r}(s)
$$

is used, in which $\tau$ is the wheelbase filtering time delay given by $w_{b} / v$. The constant $w_{b}$ is the machine wheelbase and $v$ its forward speed. All our computations and plot outputs were obtained using MATLAB ([27]) M-files.

\section{Results}

3.1 Introductory Comments. Straight running root-loci of the type presented in Fig. 3 are well known in the motorcycle literature; see, for example, [1,2,28,29].

This plot shows that the wobble mode ${ }^{4}$ is lightly damped at 13 $\mathrm{m} / \mathrm{s}(29 \mathrm{mph})$ and that the associated resonant frequency is approximately $48 \mathrm{rad} / \mathrm{s}(7.6 \mathrm{~Hz})$. This diagram also shows that the weave mode ${ }^{5}$ becomes lightly damped at high speeds and that the resonant frequency of this mode is approximately $22 \mathrm{rad} / \mathrm{s}(3.5$ $\mathrm{Hz})$ at a machine speed of $40 \mathrm{~m} / \mathrm{s}(90 \mathrm{mph})$. It should also be noted that the front wheel hop mode, ${ }^{6}$ the rear suspension bounce (pitch) mode, ${ }^{7}$ and the front suspension bounce (pitch) mode ${ }^{8}$ are relatively insensitive to variations in the machine speed. This observation reinforces the notion that the in-plane and out-of-plane dynamics are decoupled from each other under straight running conditions. We should also observe that in-plane disturbances such as sinusoidal road undulations will not couple at first-order level into out-of-plane freedoms such as the roll and steering angles.

Let us now contrast Figs. 3 and 4 with the help of Figs. 5 and 6. Figure 4 shows the behavior of the important machine modes under cornering at different speeds at a fixed roll angle - in this case $30 \mathrm{deg}$. Figures 5 and 6 show the effect of varying the machine roll angle at two constant speed values $13 \mathrm{~m} / \mathrm{s}(29 \mathrm{mph})$ and $40 \mathrm{~m} / \mathrm{s}(90 \mathrm{mph})$. When one compares these plots, it can be seen that

${ }^{4}$ This is sometimes called the wheel shimmy mode and is associated with a front wheel castoring type oscillation.

${ }^{5}$ This is associated with a $2-4 \mathrm{~Hz}$ fish tailing motion involving the simultaneous rolling and yawing of the whole machine.

${ }^{6}$ This mode is associated with an oscillation that involves the compression and expansion of the fork legs and the tire carcass.

${ }^{7}$ This mode is associated with an oscillatory motion of the swinging arm. This movement results in the pitching, and to a lesser extent, the heaving of the machine's main body.

${ }^{8}$ This mode is dominated by a pitching motion that hinges around the rear wheel ground contact point and involves the oscillatory compression and expansion of the fork leg assemblies. When this mode is excited there is also a discernible heaving of the machine's main body. 


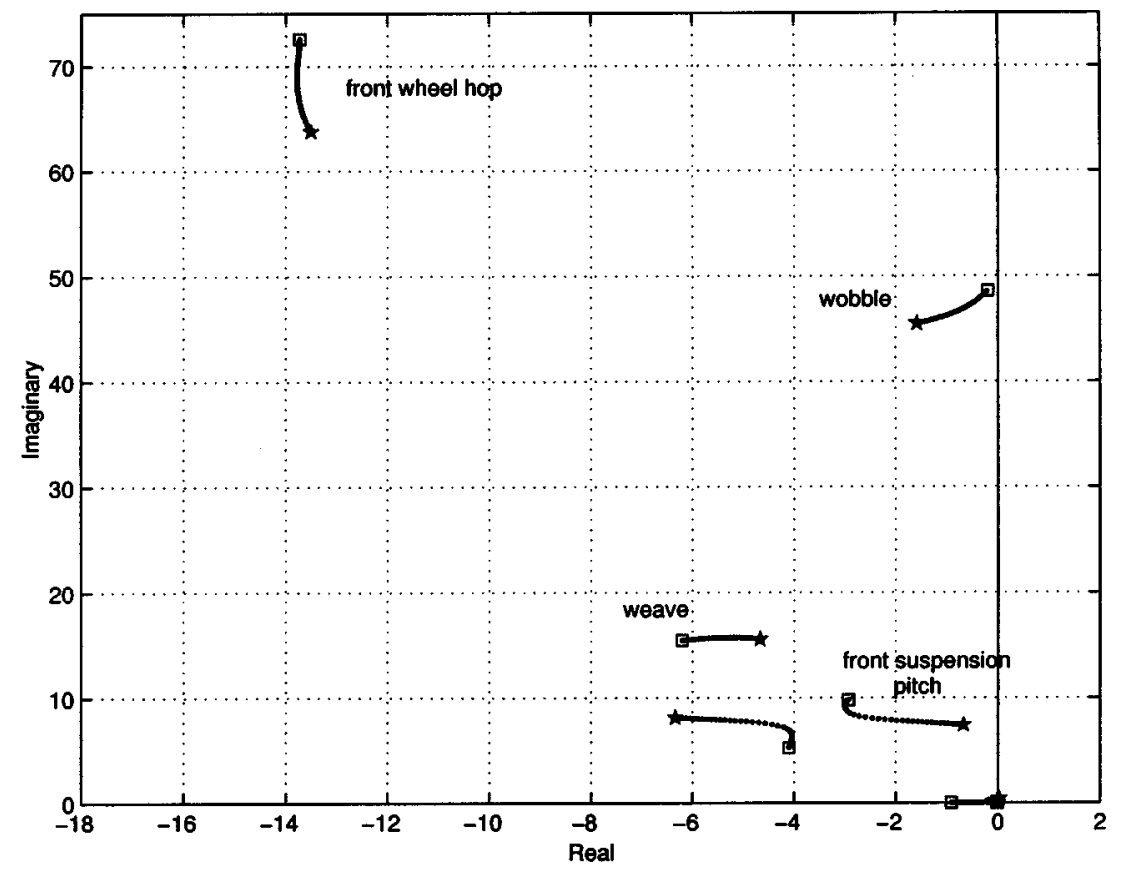

Fig. 5 Root-locus for a fixed speed of $13 \mathrm{~m} / \mathrm{s}(29 \mathrm{mph})$. The roll angle in increased from $0,(\square)$ to $30 \mathrm{deg}(\star)$.

1. cornering increases the damping of the wobble mode, while the speed for minimum damping remains at approximately $13 \mathrm{~m} / \mathrm{s}(29 \mathrm{mph})$. The associated resonant frequency of this mode is essentially unaffected.

2. cornering reduces the damping of the front wheel hop mode and it is least damped at approximately $40 \mathrm{~m} / \mathrm{s}(90 \mathrm{mph})$ with an associated resonant frequency of approximately 63 $\mathrm{rad} / \mathrm{s}(10 \mathrm{~Hz})$. This figure is lower than the straight running figure of $73 \mathrm{rad} / \mathrm{s}(11.6 \mathrm{~Hz})$.
3. cornering tends to reduce the damping of the weave mode and in our case this mode becomes unstable at high speed; the weave mode is lightly damped at $40 \mathrm{~m} / \mathrm{s}$ (90 mph).

4. cornering has a destabilizing effect on the front suspension pitch mode and it becomes particularly lightly damped at $13 \mathrm{~m} / \mathrm{s}$ and $30 \mathrm{deg}$ of roll angle. The resonant frequency of this mode is approximately $8 \mathrm{rad} / \mathrm{s}(1.27 \mathrm{~Hz})$ under these conditions.

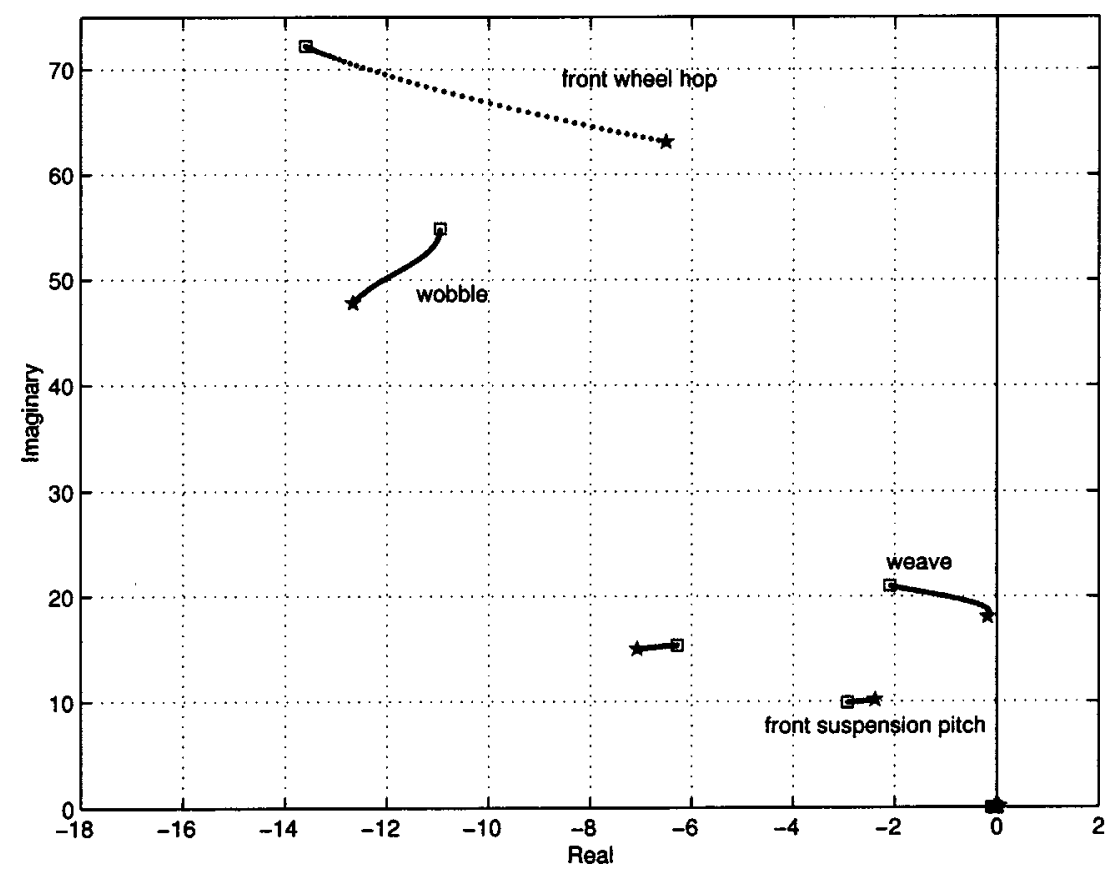

Fig. 6 Root-locus for a fixed speed of $40 \mathrm{~m} / \mathrm{s}(90 \mathrm{mph})$. The roll angle in increased from $0,(\square)$ to $30 \mathrm{deg}(\star)$. 

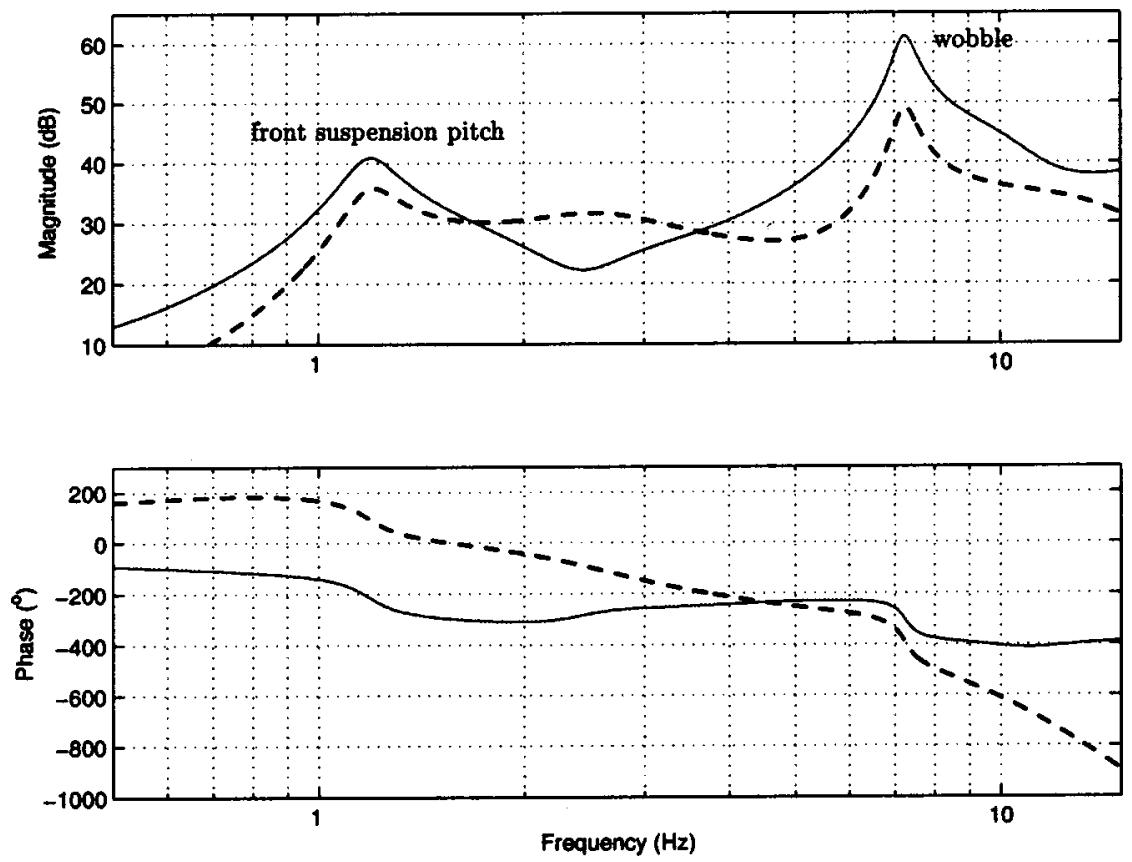

Fig. 7 Frequency response for $g_{f}(s)$ (solid), and $e^{-s \tau} g_{r}(s)$ (dashed) $(0 \mathrm{~dB}=1 \mathrm{deg} /$ $\mathrm{m})$. The steady-state conditions are a $\mathbf{3 0} \mathrm{deg}$ roll angle and a forward speed of 13 $\mathrm{m} / \mathrm{s}(29 \mathrm{mph})$.
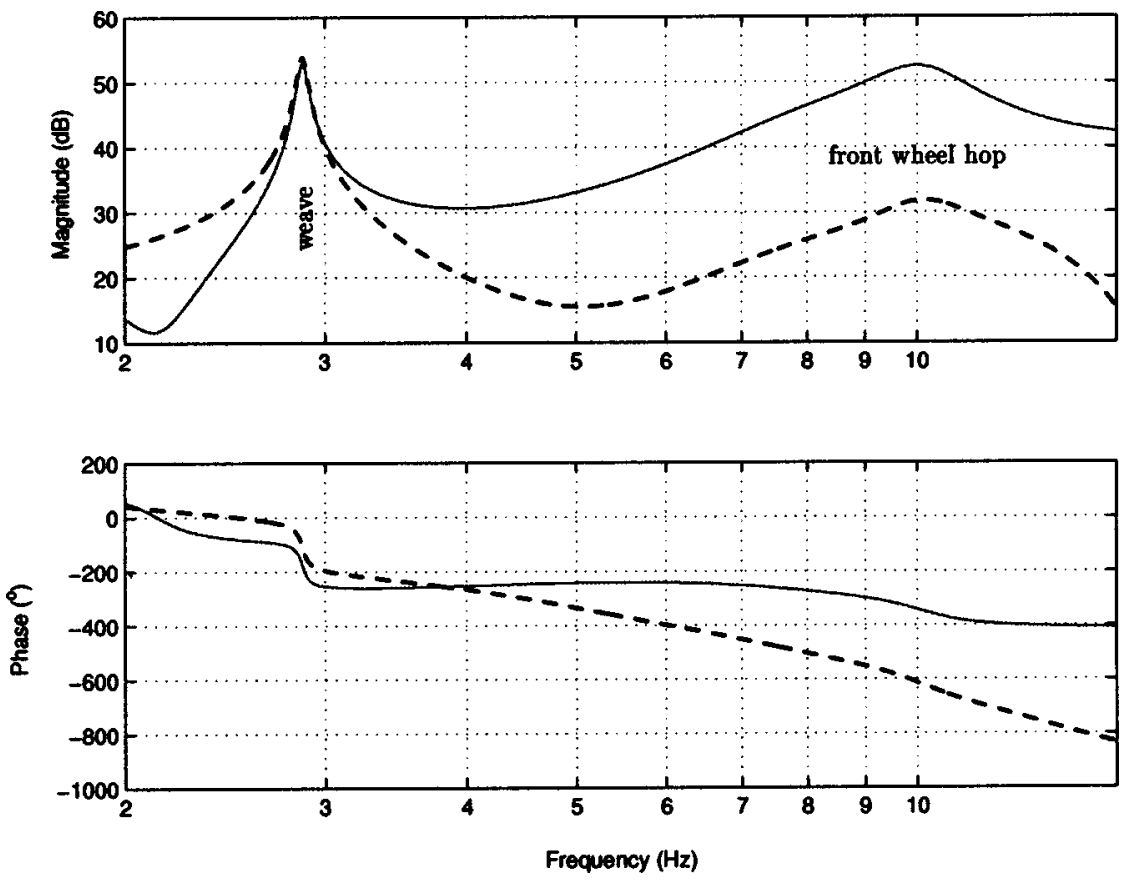

Fig. 8 Frequency response for $g_{f}(s)$ (solid), and $e^{-s \tau} g_{r}(s)$ (dashed) $(0 \mathrm{~dB}=1 \mathrm{deg} /$ $\mathrm{m})$. The steady-state conditions are a $\mathbf{3 0} \mathrm{deg}$ roll angle and a forward speed of $\mathbf{4 0}$ $\mathrm{m} / \mathrm{s}$ (90 mph).

Since road forcing signals will couple into out-of-plane freedoms under cornering, these observations lead to the following hypotheses:

1. The wobble and front suspension pitch modes are exposed to resonant forcing due to road profiling at speeds of the order $13 \mathrm{~m} / \mathrm{s}(29 \mathrm{mph})$, and

2. the weave and front wheel hop modes are similarly vulnerable at high speeds.
3. Since the coupling between road disturbances and the outof-plane dynamics increases with roll angle, we expect to find an increase in the vulnerability of the front wheel hop mode, the weave mode, and the front suspension pitch mode with roll angle. All three modal dampings decrease with increased roll angle.

4. We expect the vulnerability of the wobble mode to reach a peak at some worst-case value of roll angle. We suggest this 


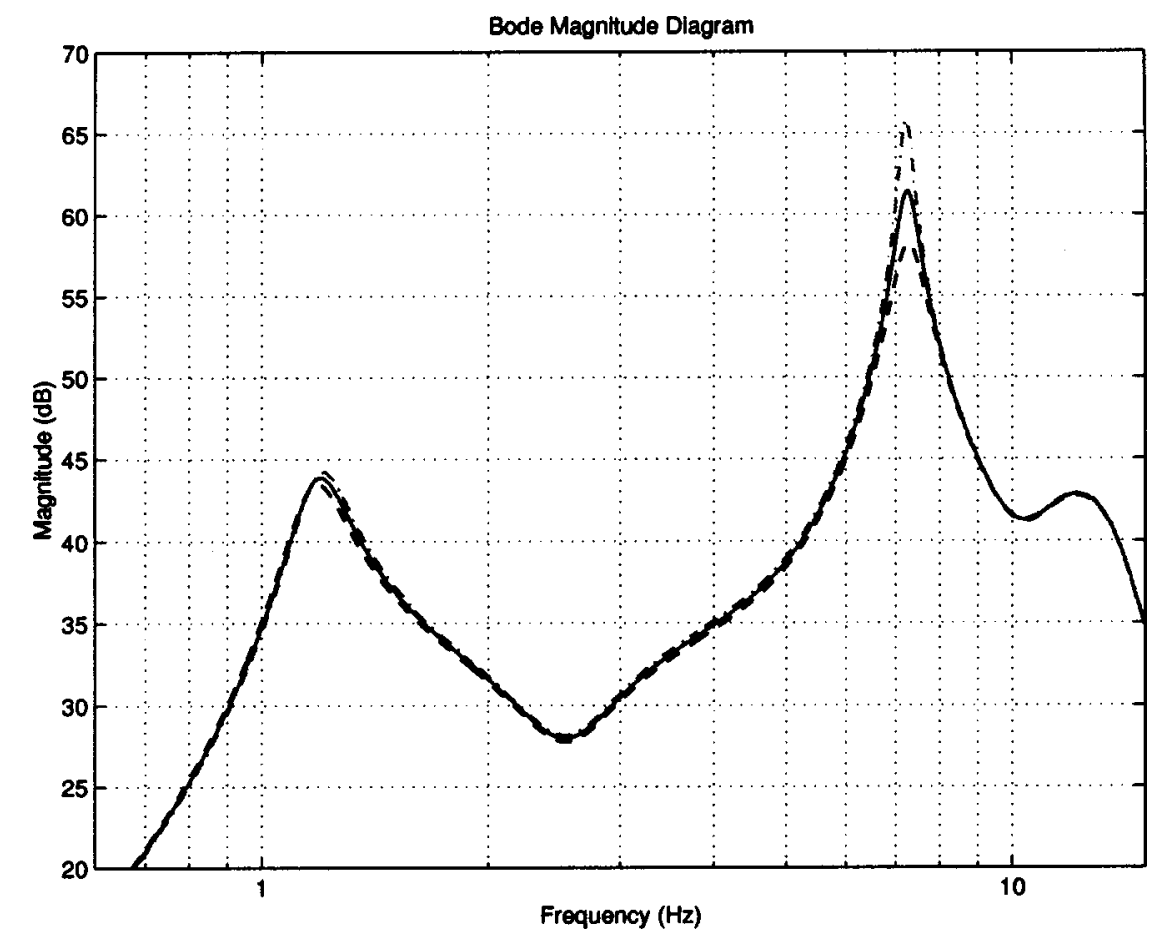

Fig. 9 Bode magnitude plot of $g(s)(0 \mathrm{~dB}=1 \mathrm{deg} / \mathrm{m})$. Nominal state: $13 \mathrm{~m} / \mathrm{s}(29$ $\mathrm{mph}$ ), $30 \mathrm{deg}$ roll angle. The solid curve represents the nominal case, the dashed one shows the effect of an increase of $20 \%$ in the steering damper setting, while the dot-dash curve shows the effect of a $20 \%$ reduction in the steering damping.

because the interplane coupling increases with roll angle, while the damping of the wobble mode increases with roll angle.

It is the business of the remainder of this paper to investigate these conjectures.

3.2 Individual Wheel Contributions. Figure 7 shows Bode plots of $g_{f}(s)$ and $e^{-s \tau} g_{r}(s)$ at the relatively low speed of $13 \mathrm{~m} / \mathrm{s}$ (29 $\mathrm{mph})$, a roll angle of $30 \mathrm{deg}$ and with nominal parameter values. It is clear from these plots that the resonant peaks for both the wobble and front suspension pitch modes are front-wheelinput dominated. The difference between the front and rear wheel excited resonant peaks for the wobble mode is $12 \mathrm{~dB}$, while that for the front suspension pitch mode is approximately $5 \mathrm{~dB}$. We conclude, therefore, that difficulties with either of these modes will almost certainly be ameliorated via adjustments to the front of the machine.

The situation at higher speeds is quite different as is shown in Fig. 8. At $40 \mathrm{~m} / \mathrm{s}(90 \mathrm{mph})$ and $30 \mathrm{deg}$ of roll, we see that there are resonance peaks associated with the weave and the front wheel hop modes. In the case of the weave mode, the front and rear wheel forcing signals are making equal contributions and their combined effect is a large one. Resonance difficulties with this mode are likely to be more difficult to isolate and prevent, because the problem involves potentially the geometry and parameters of the whole machine as well as the properties of both tires. The excitation of the front wheel hop mode is due almost entirely to front wheel forcing and is consequently a problem that can be isolated and tackled at the front of the bike.

At the weave mode peak, the frequency responses $g_{f}(s)$ and $e^{-s \tau} g_{r}(s)$ have a phase angle difference of approximately $56 \mathrm{deg}$. As the motorcycle speed changes, the phase shift $e^{-s \tau}$ associated with the wheelbase travel time changes. In principle, therefore, changing the speed will influence the maximum gain, not only through affecting the modal damping factor, but also through influencing the phase angle. However, changing the speed from 38 to $42 \mathrm{~m} / \mathrm{s}$ ( $85 \mathrm{mph}$ to $95 \mathrm{mph}$ ) only changes the phase lag, at the weave mode frequency of $18 \mathrm{rad} / \mathrm{s}(2.86 \mathrm{~Hz})$, by about $4 \mathrm{deg}$. Quantitatively, therefore, the reinforcement/cancellation issue is a small one.

3.3 Low-Speed Forced Oscillations. The root-loci presented in Fig. 5 suggest that road forcing effects may cause the wobble and front suspension pitch modes to resonate at low speeds in response to regular road profiling. We begin our investigation of this possibility by referring to Fig. 9 that shows a frequency response plot that relates road forcing inputs to the vehicle's steer angle. The road profile input is in meters, while the output is in degrees. If the vehicle is traveling at $13 \mathrm{~m} / \mathrm{s}(29 \mathrm{mph})$, road undulations with a wavelength of $1.8 \mathrm{~m}(5.85 \mathrm{ft})$, will generate a road forcing signal with a frequency of $45.4 \mathrm{rad} / \mathrm{s}(7.22$ $\mathrm{Hz}$ ). Since the transfer function gain is approximately $62 \mathrm{~dB}$ at this frequency, Fig. 9 indicates that one can expect \pm 1.28 deg of steering movement for road undulations with amplitude $\pm 1 \mathrm{~mm}$. If we assume that the steering head mechanism can move through approximately \pm 20 deg from lock to lock, the linear model would suggest that road undulations of $\pm 15 \mathrm{~mm}$ will produce a sustained "tank slapping" action. ${ }^{9}$ This figure also shows that road undulations could excite the front wheel hop mode, but the gain is only approximately $44 \mathrm{~dB}$ in this case.

Immediately, it is of interest to consider the influences of design and/or suspension parameter changes on the resonant peaks. Figure 9 also shows the effect of changing the steering damper setting by $\pm 1.5 \mathrm{Nms} / \mathrm{rad}$ around the nominal value of $7.4 \mathrm{Nms} / \mathrm{rad}$. Decreasing the steering damper setting causes the road forcing gain to increase to $66 \mathrm{~dB}$, while increasing it reduces the gain to $58 \mathrm{~dB}$.

The root-loci presented in Fig. 5 demonstrate an increase in the wobble mode damping with increased roll angle. As a consequence, we predicted that a reduction in roll angle could lead to an increase (rather than a decrease) in the wobble mode peak gain

\footnotetext{
${ }^{9}$ Note that this is only an estimate from a linearized model—see Section 3.6 for
} more on nonlinear effects. 


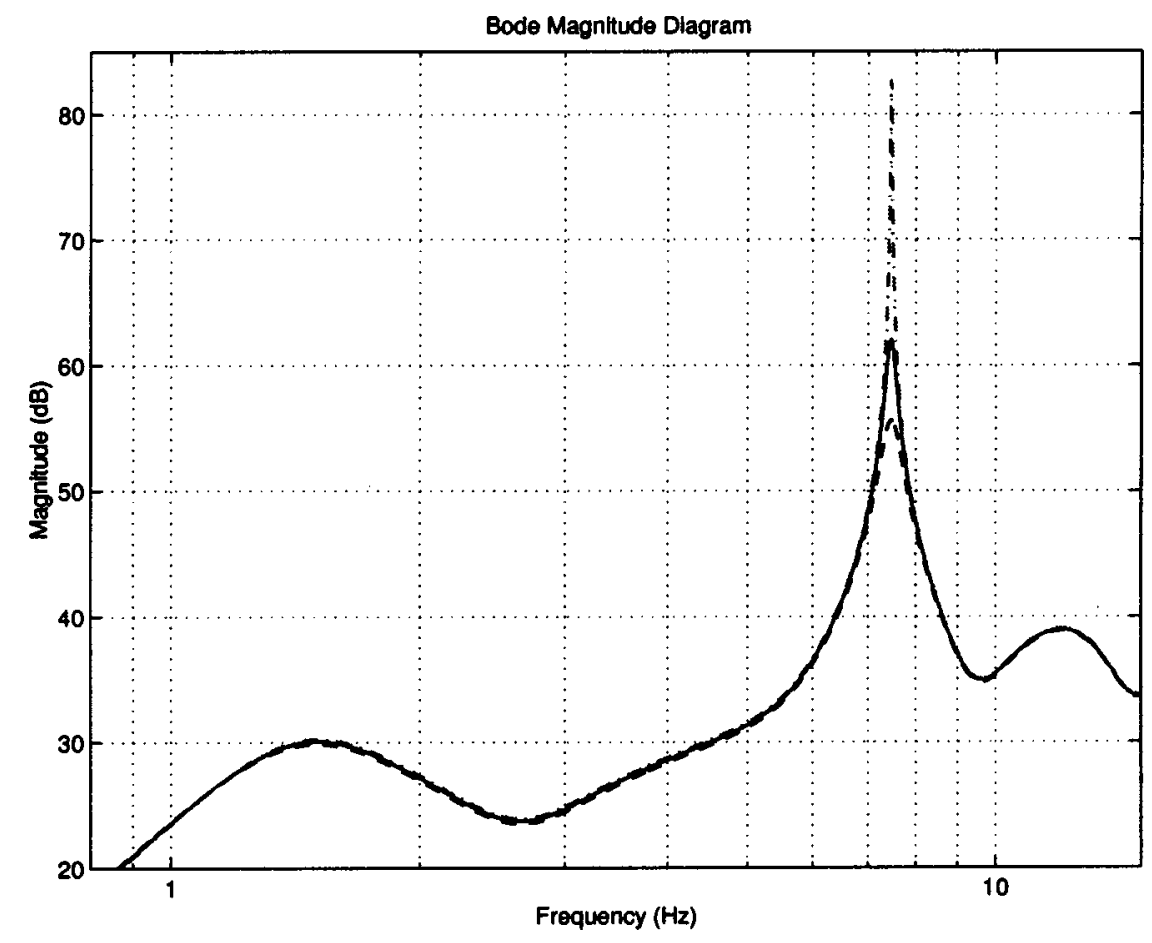

Fig. 10 Bode magnitude plot of $g(s)(0 \mathrm{~dB}=1 \mathrm{deg} / \mathrm{m})$. Nominal state: $13 \mathrm{~m} / \mathrm{s}(29$ $\mathrm{mph}), 15 \mathrm{deg}$ roll angle. The solid curve represents the nominal case, the dashed one shows the effect of an increase of $20 \%$ in the steering damping, while the dotdash curve shows the effect of a $20 \%$ decrease.

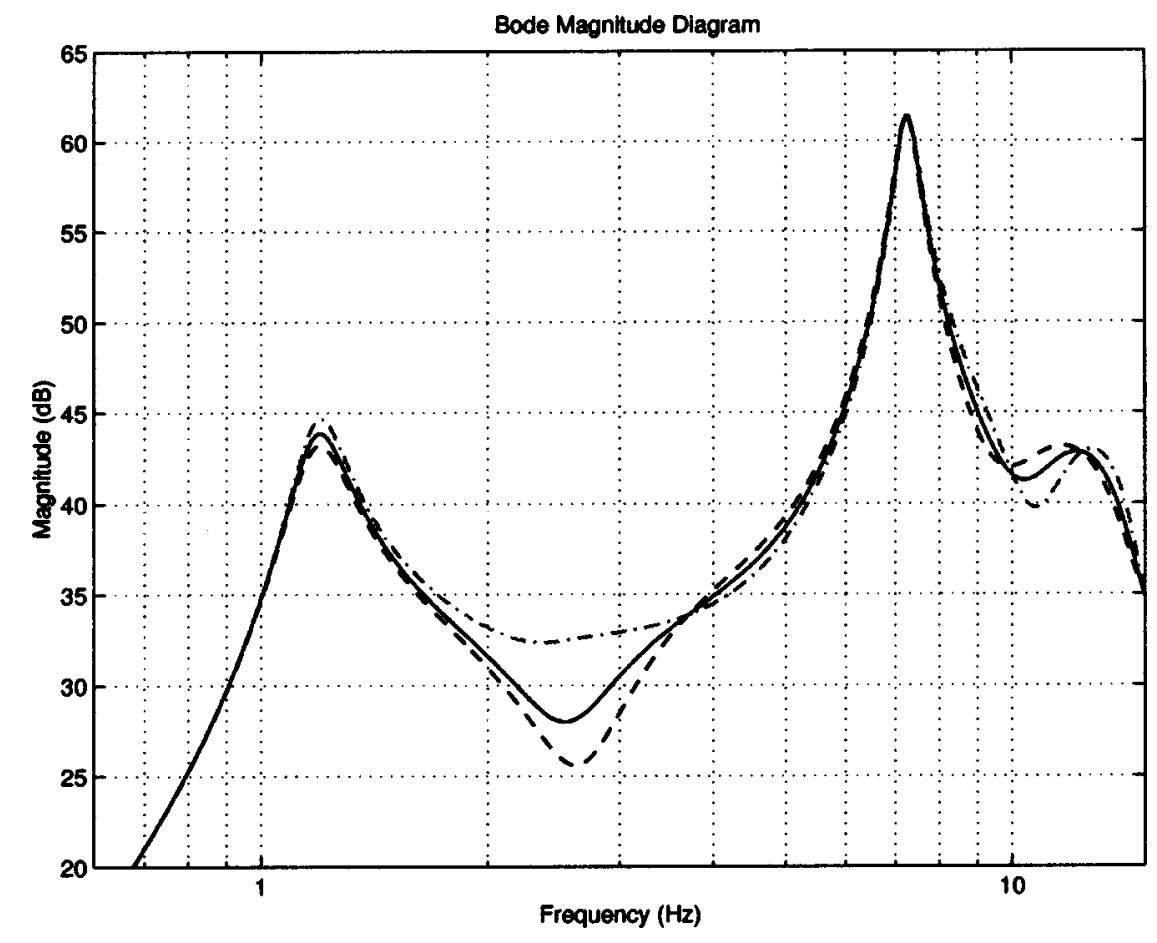

Fig. 11 Bode magnitude plot of $g(s)(0 \mathrm{~dB}=1 \mathrm{deg} / \mathrm{m})$. Nominal state: $13 \mathrm{~m} / \mathrm{s}(29$ $\mathrm{mph}$ ), $30 \mathrm{deg}$ roll angle. The solid curve represents the nominal case, the dashed one shows the effect of an increase of $40 \%$ in the rear damper setting, and the dot-dash curve shows the effect of a $40 \%$ decrease. 


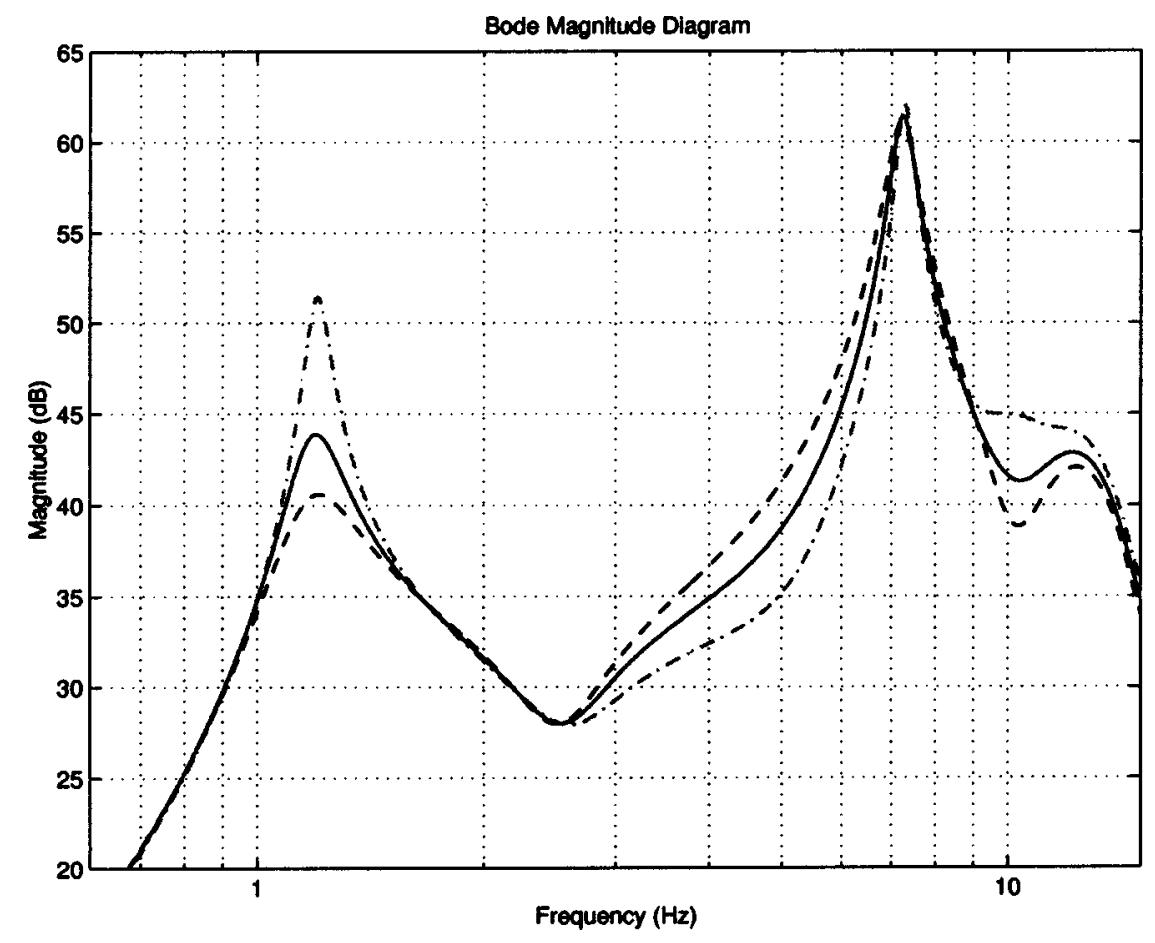

Fig. 12 Bode magnitude plot of $g(s)(0 \mathrm{~dB}=1 \mathrm{deg} / \mathrm{m})$. Nominal state: $13 \mathrm{~m} / \mathrm{s}(29$ $\mathrm{mph}$ ), $30 \mathrm{deg}$ roll angle. The solid curve represents the nominal case, the dashed one shows the effect of an increase of $40 \%$ in the front damper setting and the dot-dash curve shows the effect of a $40 \%$ decrease.

despite an accompanying reduction in the coupling between the in-plane and out-of-plane dynamics. Figures 9 and 10 show that the peak wobble mode gain for the $15 \mathrm{deg}$ and $30 \mathrm{deg}$ roll angle cases are roughly equal at $62 \mathrm{~dB}$ for the nominal value of steering damping. An increase of $20 \%$ in the steering damping decreases the peak wobble mode gain to approximately $55 \mathrm{~dB}$ (rather than $58 \mathrm{~dB}$ in the case of $30 \mathrm{deg}$ of roll). When the steering damping is decreased by $20 \%$, the peak wobble mode gain increases to $83 \mathrm{~dB}$ which is substantially higher than the peak gain achieved at 30 deg of roll angle.

Figure 11 shows that changing the rear damper setting has little impact on the susceptibility of the wobble and front suspension pitch modes to road forcing. This result casts doubt on the suspected contributions of the rear damper to the wobble mode instability associated with the Suzuki TL1000 ([17]).

As one would expect, the damping of the front suspension pitch mode, and consequently the road forcing gain associated with that mode, is influenced by changes in the front suspension damper setting. Figure 12 shows the effect of changing this damper setting by $\pm 220 \mathrm{Ns} / \mathrm{m}$ about a nominal setting of $550 \mathrm{Ns} / \mathrm{m}$. Although the wobble mode gain is relatively unaffected by these changes, the impact on the pitch mode is significant and it can be seen that a reduction of $220 \mathrm{Ns} / \mathrm{m}$ leads to a gain increase of $8 \mathrm{~dB}$ over the nominal value.

3.4 High-Speed Forced Oscillations. At the beginning of Section 3, we argued that at high speeds the weave and front wheel hop modes are vulnerable to regular road waves of critical dimensions. The consequent forced oscillations are a significant potential threat to the motorcyclist, because it is a high-speed phenomenon and for typical motorcycle parameters, longwavelength low-amplitude road undulations will excite these modes. Also, regular long-wavelength low-amplitude undulations are virtually impossible for the rider to see. At a speed of $40 \mathrm{~m} / \mathrm{s}$ (90 $\mathrm{mph}$ ) with the motorcycle parameters used here, the weave mode will be excited by road undulations with a wavelength of approximately $14 \mathrm{~m}(45.5 \mathrm{ft})$, while a $4 \mathrm{~m}(13 \mathrm{ft})$ wavelength will excite the front wheel hop mode.

Figure 13 show a Bode magnitude plot of the transfer function that relates the steering angle to regular road height variations. For nominal suspension and steering damper settings, the weave mode gain at $18 \mathrm{rad} / \mathrm{s}(2.86 \mathrm{~Hz})$ is $58 \mathrm{~dB}$, while the front wheel hop mode gain is $52 \mathrm{~dB}$. As in the case of wobble mode excitation, this diagram shows that relatively low-amplitude road undulations will cause the rider concern. This plot also shows that an increase in the steering damper setting will make matters significantly worse. More particularly, a steering damping increase of $1.5 \mathrm{Nms} /$ rad increases the road forcing gain by $10 \mathrm{~dB}$, or a factor of 3 .

Figure 13 also shows that the steering damper setting has little impact on the front wheel hop resonance.

Figure 14 shows the effect of changes to the rear damper setting. As with the steering damper, an increase in the rear damping increases the weave mode gain by $5 \mathrm{~dB}$, while reducing this damper setting causes the peak value of weave gain to fall by 4 $\mathrm{dB}$. Also, it is clear that this change has virtually no influence on the front wheel hop peak gain that remains fixed at approximately $52 \mathrm{~dB}$.

Figure 15 shows the effect of changes to the front damping. In contrast to the previous two plots, this diagram shows that increasing the front damper setting has a beneficial impact on the weave and front wheel hop gain peaks. An increase of $220 \mathrm{Ns} / \mathrm{m}$ in the front damper coefficient reduces the weave gain peak and the front wheel hop gain peak by approximately $2 \mathrm{~dB}$. If the front damping is reduced by a like amount, the weave mode gain peak increases by approximately $3 \mathrm{~dB}$ and the front wheel hop gain peak increases by approximately $6 \mathrm{~dB}$.

3.5 Influence of Rider Parameters. There is anecdotal evidence to suggest that the weight and posture of the rider can influence the vulnerability of the motorcycle-rider system to 


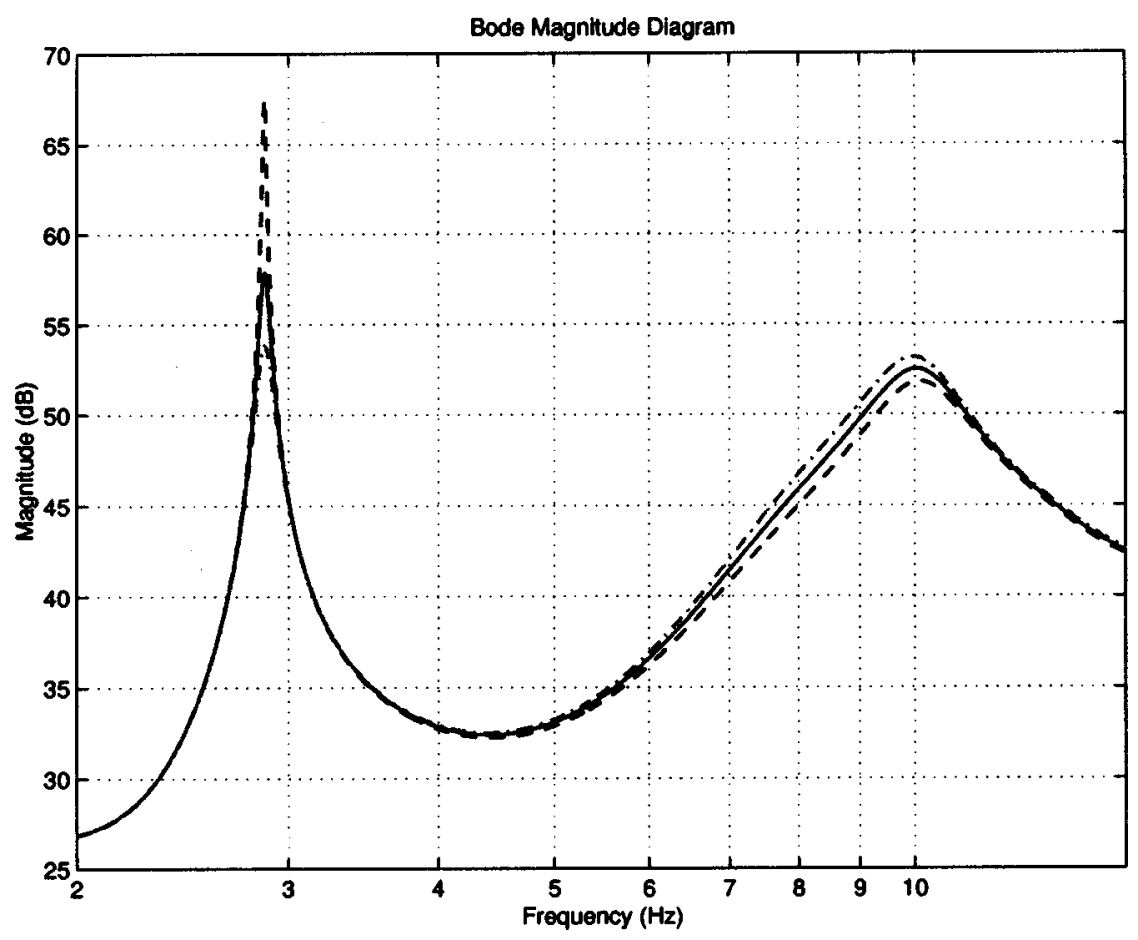

Fig. 13 Bode magnitude plot of $g(s)(0 \mathrm{~dB}=1 \mathrm{deg} / \mathrm{m})$. Nominal state: $40 \mathrm{~m} / \mathrm{s}(90$ $\mathrm{mph}$ ), $30 \mathrm{deg}$ roll angle. The solid curve represents the nominal case, the dashed one shows the effect of an increase of $20 \%$ in the steering damper setting and the dot-dash curve shows the effect of a $20 \%$ decrease.

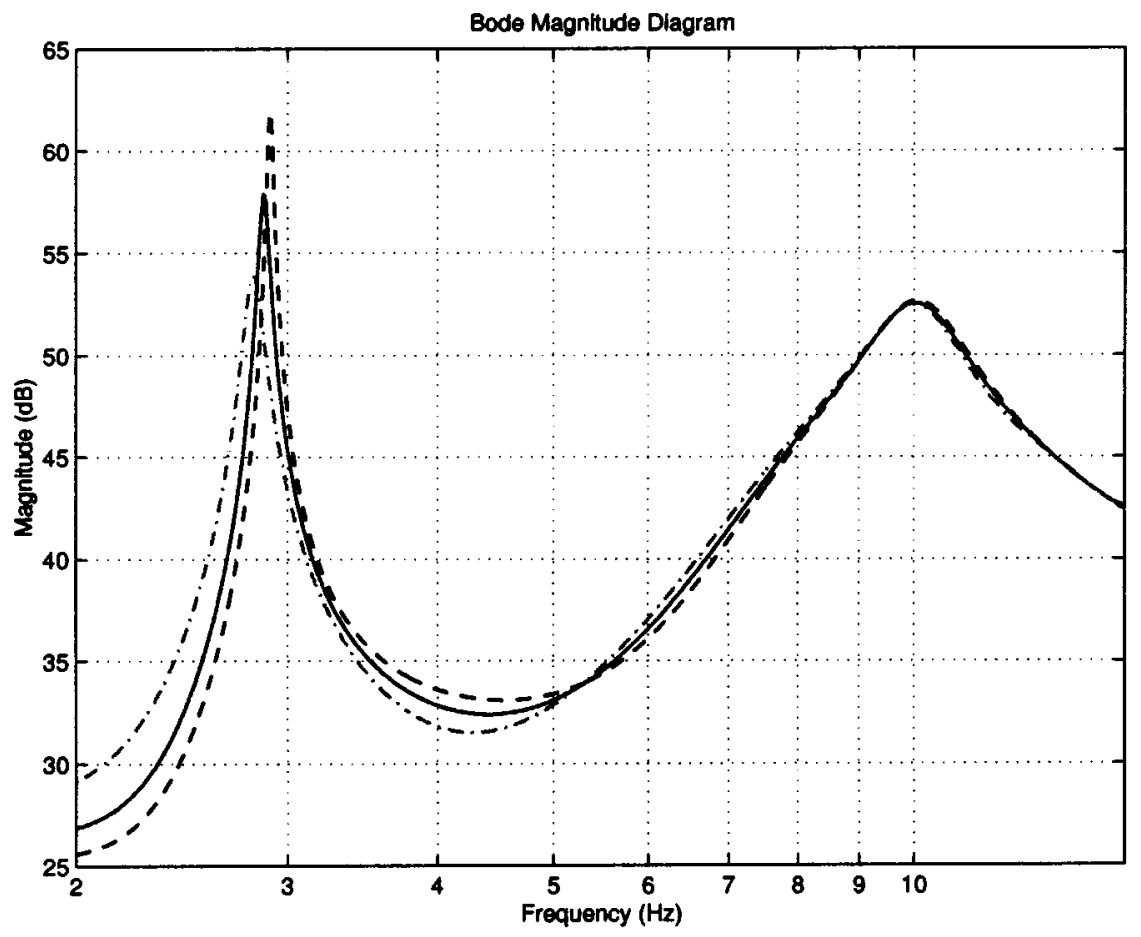

Fig. 14 Bode magnitude plot of $g(s)(0 \mathrm{~dB}=1 \mathrm{deg} / \mathrm{m})$. Nominal state: $40 \mathrm{~m} / \mathrm{s}(90$ $\mathrm{mph}$ ), 30 deg roll angle. The solid curve represents the nominal case, the dashed one shows the effect of an increase of $40 \%$ in the rear damper setting and the dot-dash curve shows the effect of a $40 \%$ decrease. 


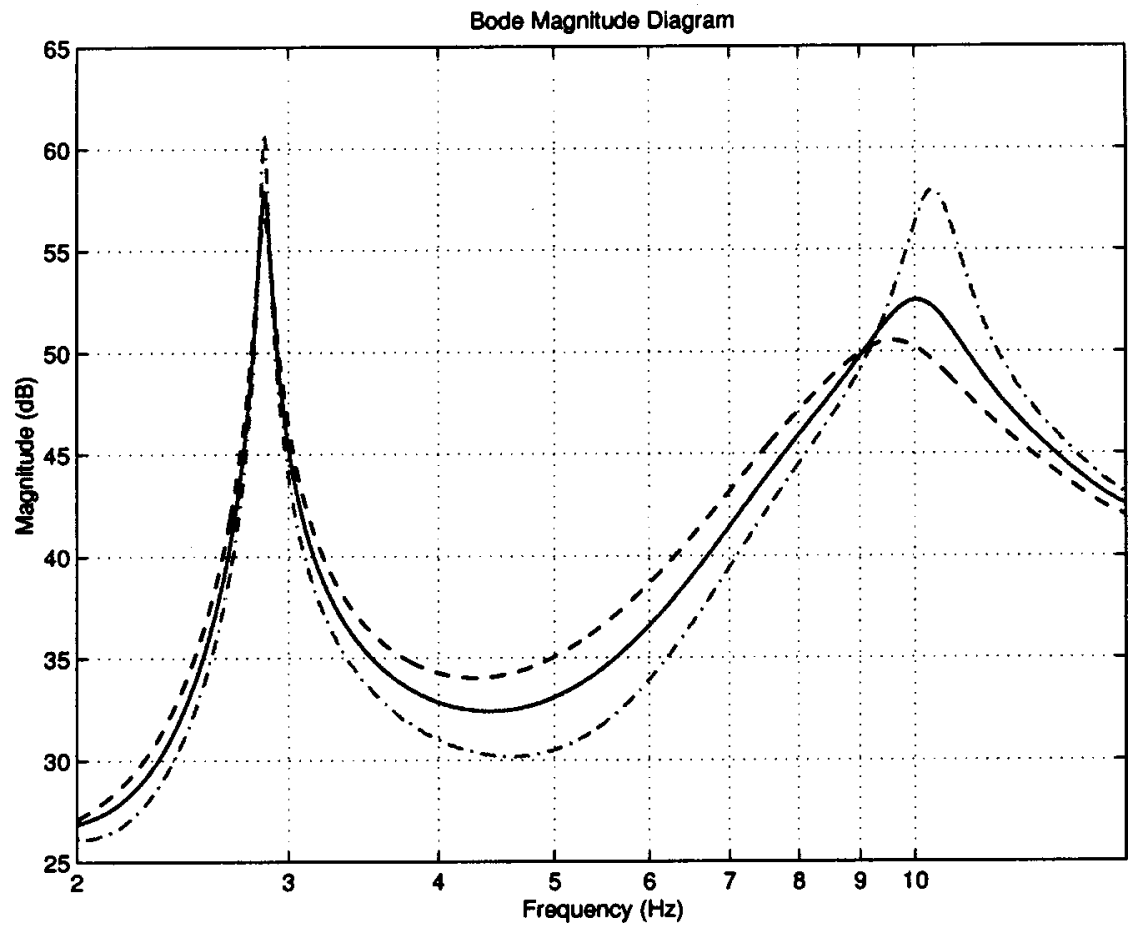

Fig. 15 Bode magnitude plot of $g(s)(0 \mathrm{~dB}=1 \mathrm{deg} / \mathrm{m})$. Nominal state: $40 \mathrm{~m} / \mathrm{s}(90$ $\mathrm{mph}$ ), $30 \mathrm{deg}$ roll angle. The solid curve represents the nominal case, the dashed one shows the effect of an increase of $40 \%$ in the front damper setting and the dot-dash curve shows the effect of a $40 \%$ decrease.

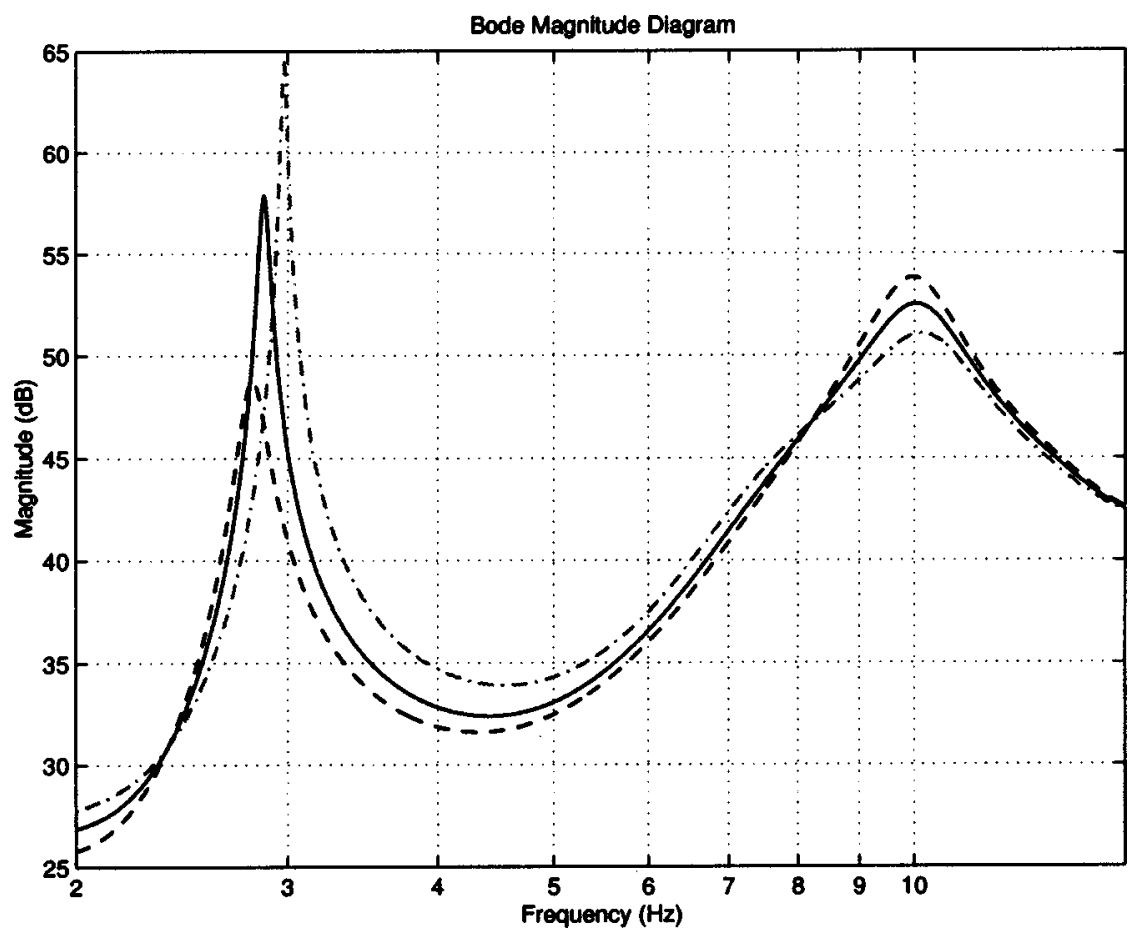

Fig. 16 Bode magnitude plot of $g(s)(0 \mathrm{~dB}=1 \mathrm{deg} / \mathrm{m})$. Nominal state: $40 \mathrm{~m} / \mathrm{s}(90$ $\mathrm{mph}$ ), $30 \mathrm{deg}$ roll angle. The solid curve represents the nominal case, the dashed one shows the effect of an increase of $20 \mathrm{~kg}(4.1 \mathrm{lbs})$ in the mass of the upper body of the rider and the dot-dash curve shows the effect of a $20 \mathrm{~kg}(4.1 \mathrm{lbs})$ decrease. 


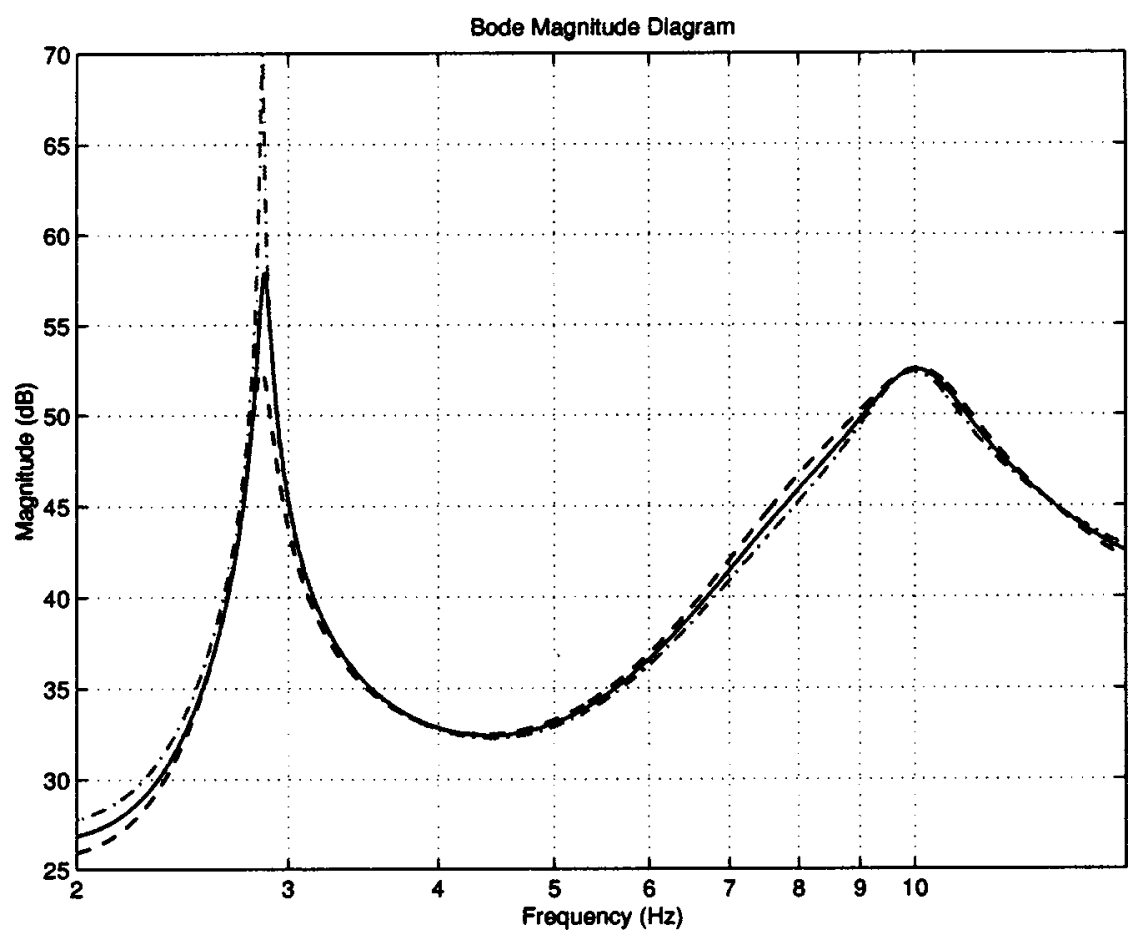

Fig. 17 Bode magnitude plot of $g(s)(0 \mathrm{~dB}=1 \mathrm{deg} / \mathrm{m})$. Nominal state: $40 \mathrm{~m} / \mathrm{s}(90$ $\mathrm{mph}$ ), $30 \mathrm{deg}$ roll angle. The solid curve represents the nominal case, the dashed one shows the effect of a forward shift of $15 \mathrm{~cm}(5.91$ ins) in the center of mass of the upper body of the rider and the dot-dash curve shows the effect of a rearward shift of $15 \mathrm{~cm}$ (5.91 ins).

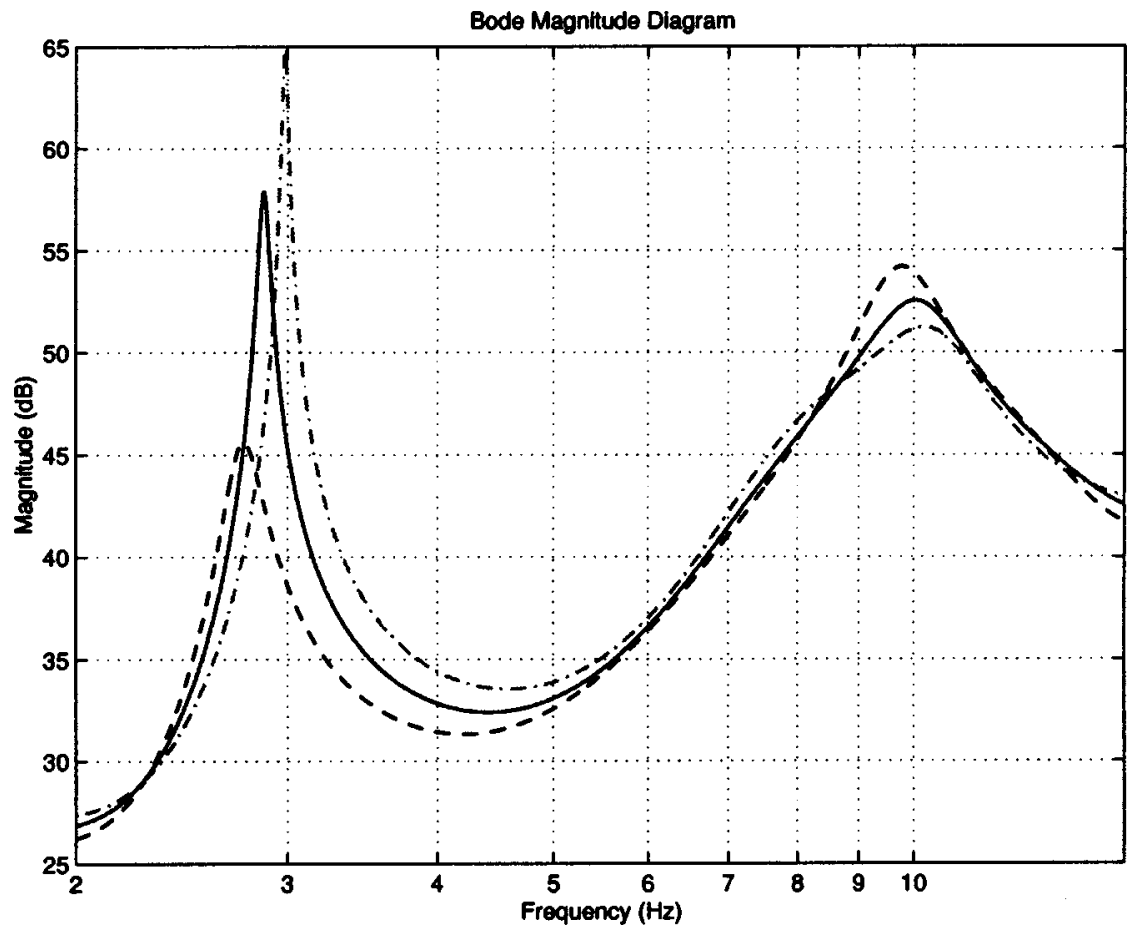

Fig. 18 Bode magnitude plot of $g(s)(0 \mathrm{~dB}=1 \mathrm{deg} / \mathrm{m})$. Nominal state: $40 \mathrm{~m} / \mathrm{s}(90$ $\mathrm{mph}), 30 \mathrm{deg}$ roll angle. The solid curve represents the nominal case, the dashed one shows the effect of an upward shift of $15 \mathrm{~cm}(5.91 \mathrm{ins})$ in the center of mass of the upper body of the rider and the dot-dash curve shows the effect of a downward shift of $15 \mathrm{~cm}$ (5.91 ins). 

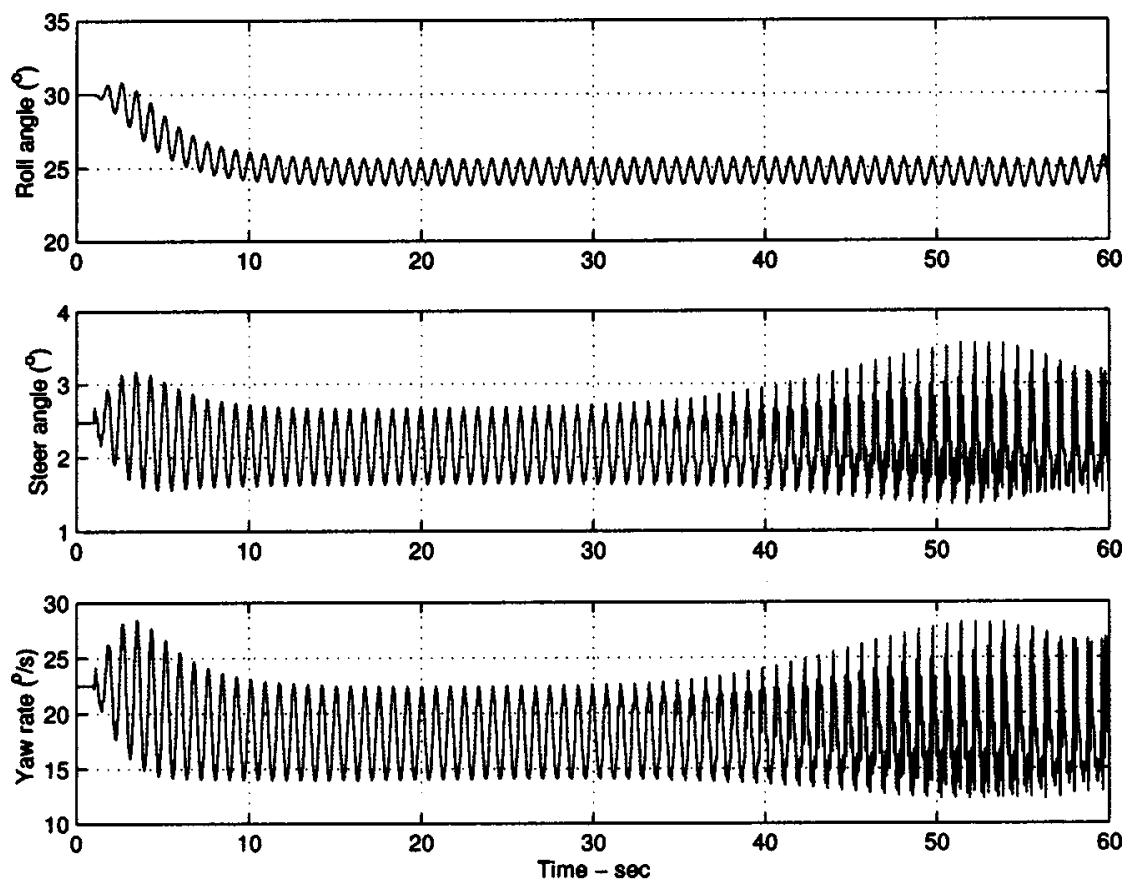

Fig. 19 Transient behavior of the roll and steering angles, and the yaw rate in response to sinusoidal road forcing that begins at $t=1 \mathrm{~s}$ and has a peak amplitude of $0.5 \mathrm{~cm}$. The forcing frequency is tuned to the front suspension pitch mode. The lean angle is $30 \mathrm{deg}$ and the forward speed $13 \mathrm{~m} / \mathrm{s}(29 \mathrm{mph})$.
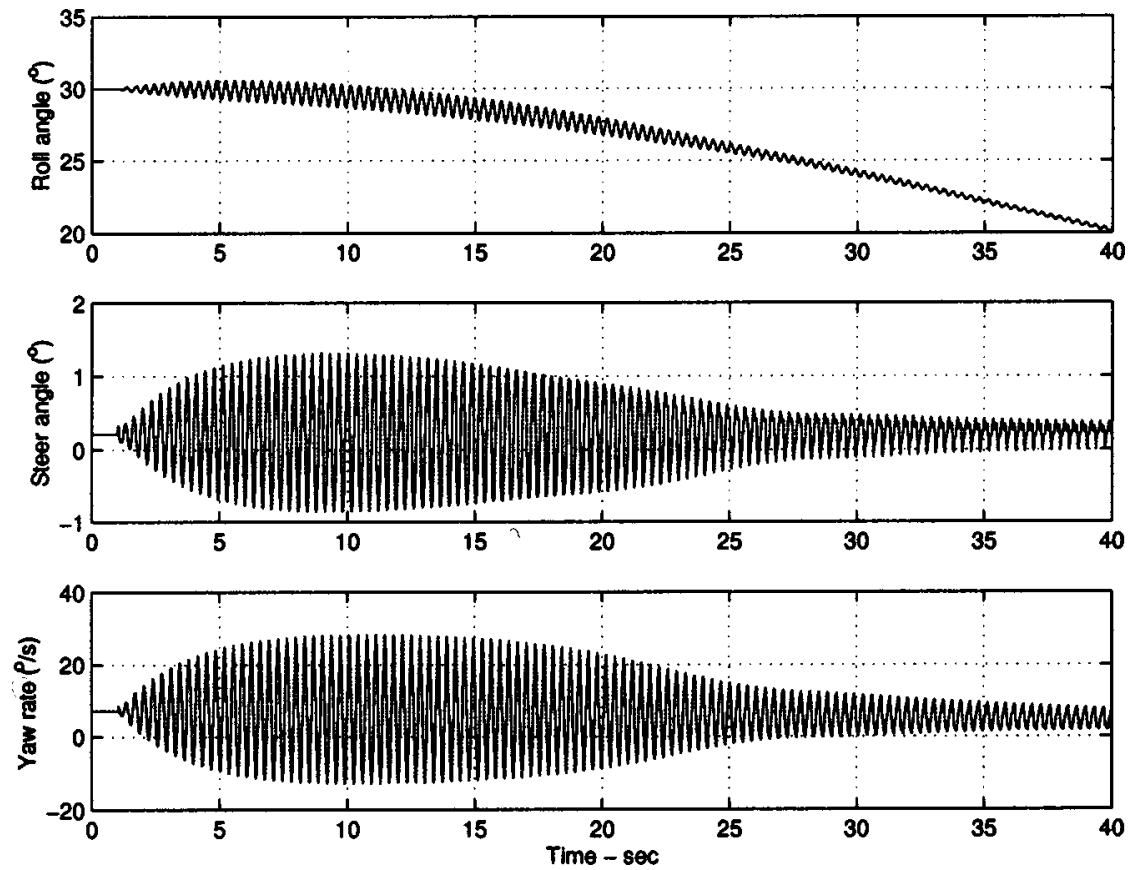

Fig. 20 Transient behavior of the roll and steer angles and the yaw rate, in response to sinusoidal road forcing that begins at $t=1 \mathrm{~s}$ and has a peak amplitude of $0.25 \mathrm{~cm}$. The forcing frequency is tuned to the weave mode. The lean angle is $\mathbf{3 0} \mathrm{deg}$ and the forward speed $40 \mathrm{~m} / \mathrm{s}(90 \mathrm{mph})$.

weave related oscillations. We will investigate the suggestion that light riders are more likely to experience difficulties with oscillatory instabilities than are heavier ones $([18,30])$. We will also investigate the suggestion that the rider can attenuate weave related oscillations by lying down on the tank ([30]). We will carry out this study at a speed of $40 \mathrm{~m} / \mathrm{s}(90 \mathrm{mph})$ and a roll angle of 30 deg, via changes in the rider's upper body mass and mass center location.

The effect of changes in the rider's upper body mass on the transfer function that maps road vertical displacement to the steer- 
ing angle are studied in Fig. 16. As suggested in [18], an increase in the rider's upper body mass by $20 \mathrm{~kg}(44.1 \mathrm{lbs})$ reduces this gain peak by approximately $8 \mathrm{~dB}$. In the same way, a reduction of the rider's upper body mass by $20 \mathrm{~kg}(44.1 \mathrm{lbs})$ increases the peak gain by approximately $7 \mathrm{~dB}$.

The effect of variations in the longitudinal location of the rider's center of mass are studied. As suggested by the video tape ([30]), a forward shift in the rider's upper body mass appears in Fig. 17 to reduce the vulnerability of the motorcycle to weave related instabilities. In our study, we see a small reduction in the signal transmission gain peak of $5 \mathrm{~dB}$ for a forward shift of $15 \mathrm{~cm}$ (5.85 ins). If the center of mass is shifted backwards by $15 \mathrm{~cm}$ (5.85 ins), the transmission gain peak increases by approximately $13 \mathrm{~dB}$.

The effect of variations in the (vertical) $z$-direction location of the rider's center of mass on the transfer function that maps road undulations to the steering angle are studied in Fig. 18. An upward shift of $15 \mathrm{~cm}$ (5.91 ins) reduces the signal transmission gain peak by $13 \mathrm{~dB}$, while a corresponding downward shift increases it by approximately $7 \mathrm{~dB}$.

3.6 Nonlinear Phenomena. Although it is not the primary purpose of this paper to study the nonlinear aspects of the road forcing problem, we do not want to conclude this account without making some introductory observations that will motivate future research. Figure 19 shows the build up of oscillations in the roll and steer angles as well as the yaw rate in response to road profiling that is tuned into the front suspension pitch mode at 7.54 $\mathrm{rad} / \mathrm{s}(1.2 \mathrm{~Hz})$. The forward speed is $13 \mathrm{~m} / \mathrm{s}(29 \mathrm{mph})$ and the forcing amplitude is $5 \mathrm{~mm}$. We can only study the very lowamplitude case here, because higher amplitude signals take the tyre model out of its domain of validity. It is evident that 7.54 $\mathrm{rad} / \mathrm{s}(1.2 \mathrm{~Hz})$ oscillations build up in 2 or 3 seconds. It can also be seen that another consequence of road forcing is a tendency for the roll angle to reduce in response to the onset of oscillations. This is possibly the result of a slow growth rate instability of the capsize type described in [1]. In practical terms, this effect will cause the vehicle to run wide, a common feature of real accidents involving oscillations. As the roll angle reduces, the road-forcing signal transmission gain will also reduce and we can see evidence of this effect in the yaw rate and steering angle oscillation amplitudes. At approximately $35 \mathrm{~s}$, one can see evidence of the onset of wobble frequency oscillations. This excitation of the wobble mode is the product of nonlinear effects that remain to be analyzed.

Figure 20 shows the response of the machine to low-amplitude road undulations that are tuned into the weave mode. Again, larger amplitude profiling will take the tire model out of its domain of validity and consequently cannot be used. In common with the previous simulation result, oscillations build up in about $3 \mathrm{~s}$. It is also evident that the roll angle tends to decrease. As can be seen in the video tape ([20]), weave-related instabilities cause the vehicle to run wide. It is also clear that as the roll angle reduces, the steer angle and yaw rate oscillations reduce in consequence. We believe that this is the result of transmission gain reductions that come about in response to reductions in the roll angle. At approximately $25 \mathrm{~s}$, one sees evidence of waveform distortion, a product of nonlinear mechanisms.

\section{Conclusions}

A study of the effects of road profiling on motorcycle steering responses is presented. The work is based on an enhanced version of the nonlinear cornering model presented in [4]. This model has been qualified using tests that are based on the principle that under equilibrium conditions all the external forces and moments acting on the motorcycle-rider system must sum to zero. We have also checked that the drive power supplied by the engine matches that dissipated by the tires and the aerodynamic forces. An AUTOSIM code was used to generate a linearized state-space model that describes small perturbations around a general equilibrium cornering state. By introducing appropriate inputs into the model, we are able to describe the propagation of road undulation signals from the tire ground contact points to the steering angle. A particular feature of the frequency response calculations is the inclusion of the wheelbase filtering.

The results show that under cornering conditions, regular lowamplitude road undulations that would not trouble four-wheeled vehicles can be a source of considerable difficulty to motorcycle riders. At low machine speeds the wobble and front suspension pitch modes are likely to respond vigorously to resonant forcing, while at higher speeds, the weave and front wheel hop modes are similarly affected. The vigour of the oscillations is related to the previously much studied linear stability properties insofar as low damping factors lead to correspondingly high peak magnification factors. Connections between resonant responses and a class of single-vehicle loss-of-rider-control accidents have been postulated.

The work reported here has a number of practical consequences. First, it appears to explain the key features of many of the stability related road traffic accidents reported in the popular literature, and it helps to explain why motorcycles that behave perfectly well for long periods can suddenly suffer serious and dangerous oscillation problems. Such oscillations are likely to be difficult to reproduce and study in practice. Secondly, road builders and maintainers, and motorcycle manufacturers, should be aware of the possibility of strong resonant responses to small but regular undulations under certain critical running conditions. These conditions are characterized by the machine speed, the lean angle, the rider's mass and posture, and the road profile wavelength. The dynamic responses are influenced by the modal damping factors, the road profiling, and the effectiveness of the forcing from the road. For our particular motorcycle, which is representative of many large machines, the wobble mode will be excited by road undulations with a wavelength of approximately $1.7 \mathrm{~m}$. This will produce a forcing signal of $7.6 \mathrm{~Hz}$ at a road speed of 13 $\mathrm{m} / \mathrm{s}$ (approximately $30 \mathrm{mph}$ ). The forcing will last for $2-3 \mathrm{~s}$, which is enough time for the resonance to build up, if there are 15-23 periods of undulation. If the undulation period is approximately $11.4 \mathrm{~m}$, a road speed of approximately $40 \mathrm{~m} / \mathrm{s}(90 \mathrm{mph})$ will produce forcing at the weave frequency of $3.5 \mathrm{~Hz}$. In this case the forcing will last for $2-3 \mathrm{~s}$ if there are 7-11 periods of undulation. It will be difficult for manufacturers to establish a set of "worst case" operating conditions to be associated with new products and yet it is essential that this is done. Thirdly, the kind of theoretical analysis presented here appears to be a necessary part of determining these worst case conditions in a reliable and economical way. This type of analysis should be an essential part of the motorcycle designer's toolkit in the future.

We have studied the individual contributions to these resonances made by each of the two road wheels. Our results show that the wobble and front wheel hop resonance peaks are "front wheel dominated." In other words, difficulties with these modes are likely to be caused by the design and set up of the front of the machine. The same is true, but to a lesser extent, in the case of the front suspension pitch mode. In contrast, the weave mode resonance peak involves the road forcing to both wheels in almost equal measure. As a consequence, weave related problems appear to be more difficult to isolate and remove.

As might be anticipated, the vulnerability of the wobble mode responses to road forcing is decreased markedly by an effective steering damper, but changes to the suspension dampers are ineffectual. The front suspension pitch mode resonance, that is associated with low-speed operation, is sensitive to the front suspension damping, but is insensitive to the rear suspension and steering damping.

In the case of high-speed operation, the weave and front wheel hop modes are exposed to road profile induced oscillations due to their low modal damping. The results show that the weave mode resonant response is reduced by increasing the front suspension damping, but it is made larger by increasing the rear suspension 
and steering damper settings. These damping results depend, of course, on the nominal setup and will not be universally true. Increasing the front suspension damping reduces the front wheel hop resonance peak, but this peak does not respond to changes in steering damping, or rear suspension damper settings.

It has also been shown that light riders are more likely to suffer from road forced resonant weave oscillations than are heavy ones, as has been observed in practice ([18]) and on the video tape ([30]). The results indicate also that the peak gains associated with the weave mode are brought down by moving the rider upper body mass forwards and upwards. There is not sufficient practical evidence at the moment to indicate whether or not these findings coincide with experience. From the rider's perspective, a worrying feature of the road profile induced oscillations is the tendency of the uncontrolled machine to "sit up" and run wide. This aspect of the machine behavior can be seen on the video tape ([20]) in the case of a high-speed weave accident.

A preliminary time domain study of these resonances by motion simulations has shown the existence of interesting and essentially nonlinear phenomena, that seem to accord with practical experience. These nonlinear phenomena are worthy of further study, together with more wide-ranging investigations of design influences on the various potentially problematic running conditions.

\section{Appendix}

AUTOSIM Commands. This Appendix contains a brief description of the AUTOSIM commands used in the paper. A much fuller account can be found in the AUTOSIM reference manual ([26]).

\section{Vector Algebra}

Autosim code

cross (v1,v2)

pos $(\mathrm{p} 1, \mathrm{p} 2)$

[fwy ] $\operatorname{dot}(v 1, v 2)$

Mathematical interpretation

the cross product between vectors $v_{1}$ and $v_{2}$ inner product between vectors $v_{1}$ and $v_{2}$ vector going from point $\mathrm{p} 2$ to point $\mathrm{p} 1$ symbol is a unit-vector when enclosed in braces

\section{References}

[1] Sharp, R. S., 1971, “The Stability and Control of Motorcycles.” J. Mech. Eng. Sci., 13(5), pp. 316-329.

[2] Sharp, R. S., 1994, Vibrational Modes of Motorcycles and Their Design Pa- rameter Sensitivities, Vehicle NVH and Refinement, Proc Int Conf., Birmingham, May 3-5, Mech. Eng. Publications, London, pp. 107-121.

[3] Limebeer, D. J. N., Sharp, R. S., and Evangelou, S., 2001, “The Stability of Motorcycles Under Acceleration and Braking," Proc. Inst. Mech. Eng., Part D (J. Automob. Eng.), 215(C9), pp. 1095-1109.

[4] Sharp, R. S. and Limebeer, D. J. N., 2001, "A Motorcycle Model for Stability and Control Analysis," Multibody Syst. Dyn., 6(2), pp. 123-142.

[5] Koenen, C., 1983, "The Dynamic Behavior of Motorcycles When Running Straight Ahead and When Cornering," Ph.D. thesis, Delft University of Technology. Delft, The Netherlands.

[6] Sharp, R. S., Limebeer, D. J. N., and Gani, M. R., 1999, “A Motorcycle Model for Stability and Control Analysis," Euromech Colloquium 404, Advances in Computational Multibody Dynamics, J. A. C. Ambrosio and W. O. Schiehlen ed., pp. 287-312.

[7] Sharp, R. S., 1992, "Wobble and Weave of Motorcycles With Reference to Police Usage," Automot. Eng., 17(6), pp. 25-27.

[8] BMW statement to all (UK) chief constables, Dec. 14, 1993.

[9] Cutts, J., 1993, "The Boxer Rebellion," Superbike, Apr., pp. 4-10.

[10] Evans, J., 1993, BMW R1100RS, Motor Cycle Int., Mar., pp. 58-64.

[11] Raymond, K., 1993, “Could do Better," Perform. Bikes, Apr., pp. 34-36.

[12] “An Interview With Dr. Goeschel," 1993, Motorcycle Sport, May, pp. 234 235.

[13] "Boxer Comeback," 1993, Which Motorcycle, Apr., pp. 26-32.

[14] Duke, O., 1997, "Planet Bike-Radical Thriller or Flawed Killer," Bike, June, pp. $14-17$.

[15] "Safety Recall Notice, American Suzuki Motor Corporation," 1997, Motorcycle, June 9.

[16] Farr, K., 1997, "Suzuki TL1000 Recalled in UK," Motorcycle News, June 18

[17] "Operating Stable," 1997, Performance Bikes, July, pp. 44-51.

[18] Farr, K., 1997, "Fats the Way To," Motorcycle News, July 2.

[19] Robinson, J., 2001, "Wobble and Weave," Performance Bikes, July, pp. 8385.

[20] Duke Marketing Ltd., 1999, "Motorcycle Magic."

[21] Farrar, S., 2002, "Orritt's Story to Explain the Phenomena," Times Higher Educational Supplement, Feb. 15.

[22] Metropolitan Police, private communication, 2000.

[23] Sharp, R. S., 2001, "The Stability, Control and Steering Responses of Motorcycles," Veh. Sys. Dyn., 35(4-5), pp. 291-318.

[24] Breuer, T., and Pruckner, A., 1998, "Advanced Dynamic Motorbike Analysis and Driver Simulation," Proc 13th European ADAMS Users' Conference, Paris, Nov. 1998, 20pp.

[25] Imaizumi, H., and Fujioka, T., 1996, “Motorcycle-Rider System Dynamics by Multibody Dynamics Analysis-Effects of the Rear Load and the Suspension Assembly on Wobble and Weave Motions," JSAE Review, 19(1), pp. 54-57.

[26] Mechanical Simulation Corporation, 1996, Autosim 2.5 + Reference Manual, http://www.trucksim.com.

[27] The Mathworks, Inc., 2000, MATLAB 6 Reference Manual, http:// www.mathworks.com.

[28] Evangelou, S., and Limebeer, D. J. N., 2000, "Lisp Programming of the "Sharp 1971" Motorcycle Model," http://www.ee.ic.ac.uk/control/ motorcycles.

[29] Evangelou, S., and Limebeer, D. J. N., 2000, "Lisp Programming of the "Sharp 1994" Motorcycle Model," http://www.ee.ic.ac.uk/control/ motorcycles.

[30] Dunlop, "Wobble and Weave Videotape," c1977. 